\title{
Synthesis and characterization of two- and three-dimensional nanolaminated carbides
}

Quanzheng Tao
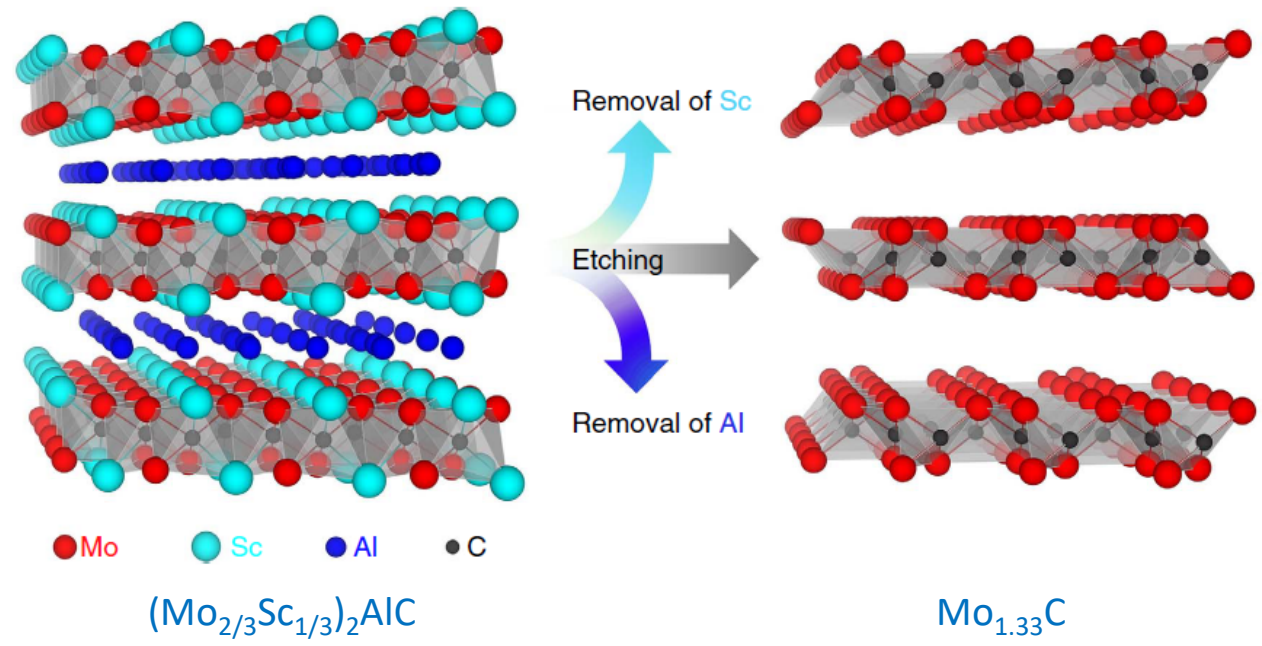


\section{Synthesis and characterization of two- and three-dimensional nanolaminated carbides}

\section{Quanzheng Tao}




\section{Abstract}

This thesis is focused towards the synthesis and characterization of novel nanolaminated materials in primarily bulk (powder) form. Of particular interest is magnetic materials, or laminates that can be used as precursor for two-dimensional (2D) materials. 2D materials typically display a large surface-to-volume ratio, and as such they are very promising for applications within energy storage and catalysis. A more recently discovered family of $2 \mathrm{D}$ transition metal carbides/nitrides, called MXenes, are currently attracting a lot of attention. MXenes are produced by selective etching of parent 3D nanolaminates, so called MAX phases, facilitating removal of selected atomic layers, and formation of $2 \mathrm{D}$ sheets.

In my work on new nanolaminates as precursors for 2D materials, I have synthesized $\left(\mathrm{Mo}_{2 / 3} \mathrm{Sc}_{1 / 3}\right)_{2} \mathrm{AlC}$ and have studied its crystal structure. It was found that Mo and $\mathrm{Sc}$ are chemically ordered in the metal layers, with the in-plane ordering motivating the notation $i$ MAX for this new type of MAX phase alloy. By selective etching of Sc and Al, we thereafter produced a $2 \mathrm{D}$ materials with ordered vacancies, $\mathrm{Mo}_{1.33} \mathrm{C}$, and studied the electrochemical properties. It was found that the material displayed a high capacitance, $\sim 1200 \mathrm{~F} \mathrm{~cm}^{-3}$, which is $65 \%$ higher that the counterpart without vacancies, $\mathrm{Mo}_{2} \mathrm{C}$.

I also synthesized a previously not known out-of-plane ordered $\mathrm{Mo}_{2} \mathrm{ScAlC}_{2} \mathrm{MAX}$ phase. By selective etching of $\mathrm{Al}$, we produced a $2 \mathrm{D}$ material, $\mathrm{Mo}_{2} \mathrm{ScC}_{2}$, which is correspondingly ordered in the out-of-plane direction. Another related laminated material was also discovered and synthesized, $\mathrm{Sc}_{2} \mathrm{Al}_{2} \mathrm{C}_{3}$, and its crystal structure was determined. The material is potentially useful for conversion into a $2 \mathrm{D}$ material. $\mathrm{I}$ have also shown that $\mathrm{Sc}_{2} \mathrm{Al}_{2} \mathrm{C}_{3}$ is an example of a series of materials with the same crystal structure, with Sc replaced by other metals.

Magnetic materials are used in many applications, such as for data storage devices. In particular, layered magnetic materials are of interest due to their anisotropic structure and potential formation of interesting magnetic characteristics. I have been synthesizing and characterizing magnetic nanolaminates, starting with the $(\mathrm{V}, \mathrm{Mn})_{3} \mathrm{GaC}_{2} \mathrm{MAX}$ phase in the form of an epitaxial thin film. Analysis of the magnetic behavior showed a ferromagnetic response above room temperature I thereafter showed that our previously discovered family of $i$-MAX phases could be expanded with a subclass of ordered nanolaminates based on rare earth (RE) elements, of the general formula $\left(\mathrm{Mo}_{2 / 3} \mathrm{RE}_{1 / 3}\right)_{2} \mathrm{AlC}$, where $\mathrm{RE}=\mathrm{Ce}, \mathrm{Pr}, \mathrm{Nd}, \mathrm{Sm}, \mathrm{Gd}, \mathrm{Tb}, \mathrm{Dy}$, Ho, Er, Tm, and Lu. I studied their crystal structure by scanning transmission microscopy (STEM), X-ray diffraction (XRD), and neutron diffraction. We found that these phases can crystalize in three different structures, of space group $\mathrm{C} 2 / \mathrm{m}, \mathrm{C} 2 / \mathrm{c}$, and $\mathrm{Cmcm}$, respectively. The magnetic behavior was studied and the magnetic structure of two materials could be determined. We suggest that the complex behavior identified is due to competing magnetic interaction and frustration. 
I also synthesized another rare earth-based nanolaminate, $\mathrm{Mo}_{4} \mathrm{Ce}_{4} \mathrm{Al}_{7} \mathrm{C}_{3}$. The crystal structure was investigated by single crystal X-ray diffraction and STEM. Magnetization analysis reveal a ferromagnetic ground state below $10.5 \mathrm{~K}$. X-ray absorption near-edge structure provide evidence that $\mathrm{Ce}$ is in a mixed-valence state. X-ray magnetic circular dichroism shows that only one of the two Ce sites are magnetic. 


\section{Populärvetenskaplig beskrivning}

Material är otroligt viktiga i vårt samhälle och i våra dagliga liv, och vi använder en stor mängd olika typer av material i de produkter vi kommer i kontakt med. Till exempel används energilagringsmaterial i Li-jon-batterier för att lagra el och för att driva våra mobiltelefoner. När tekniken utvecklas behöver vi nya material med bättre prestanda för att möta ständigt ökande krav, till exempel material som kan lagra mer el, material som är starkare, och material som tål högre temperaturer.

Jag är främst intresserad av syntes och karakterisering av nya lagrade material, bestående av staplade skikt. Lagrade material är som pannkakstårtor; dessa är gjorda av tunna lager av pannkakor som staplas ihop, medan lagrade material är tillverkade av tunna staplade atomlager. Dessa tunna atomlager är inte starkt bundna eller ihoplimmade, så det är möjligt att separera dem till enskilda flak, ungefär som att skala en lök. Efter skalningen är dessa flak typiskt omkring $1 \mathrm{~nm}$ tjocka, och med en area av flera mikrometer gånger flera mikrometer. Vi kallar dessa material för tvådimensionella material, eller 2D-material. 2D-material är utmärkta kandidater för olika tillämpningar, till exempel som material för energilagring.

Jag har syntetiserat flera nya lagrade material. Ett exempel är $\left(\mathrm{Mo}_{2 / 3} \mathrm{Sc}_{1 / 3}\right)_{2} \mathrm{AlC}$. När man upptäcker ett nytt material måste man först studera dess struktur och sammansättning, dvs vad materialet är gjort av och hur atomerna är arrangerade. Med elektronmikroskop och annan utrustning kunde vi visa att $\left(\mathrm{Mo}_{2 / 3} \mathrm{Sc}_{1 / 3}\right)_{2} \mathrm{AlC}$ är gjort av alternerande lager av $\left(\mathrm{Mo}_{2 / 3} \mathrm{Sc}_{1 / 3}\right)_{2} \mathrm{C}$ och Al. I ( $\left.\mathrm{Mo}_{2 / 3} \mathrm{Sc}_{1 / 3}\right)_{2} \mathrm{C}$-skiktet är dessutom Mo och Sc inte slumpmässigt utspridda. Istället alterneras två Mo-atomer med en Sc-atom, och bildar därmed ordning inom själva lagret.

När vi försökte dela upp det skiktade materialet $\left(\mathrm{Mo}_{2 / 3} \mathrm{Sc}_{1 / 3}\right)_{2} \mathrm{AlC}$ i enskilda tunna lager, fann vi att vi inte bara avlägsnade Al-skikten mellan $\left(\mathrm{Mo}_{2 / 3} \mathrm{Sc}_{1 / 3}\right)_{2} \mathrm{C}$, utan att vi också avlägsnade Sc. Med avlägsnande av Sc bildas vakanser eller tomrum i det kvarvarande metallkolskiktet, och därmed upptäckte vi ett nytt 2D-material med ordnade vakanser. Vi visade också att detta material är mycket lovande för energilagring.

Jag har också syntetiserat flera andra material med liknande struktur som $\left(\mathrm{Mo}_{2 / 3} \mathrm{Sc}_{1 / 3}\right)_{2} \mathrm{AlC}$. Ett exempel är $\mathrm{Mo}_{2} \mathrm{ScAlC}_{2}$, tillverkad av växlande $\mathrm{Mo}_{2} \mathrm{ScC}_{2}$-lager och Al-lager. Även i detta material kan vi ta bort Al-lager för att producera $2 \mathrm{D} \mathrm{Mo}_{2} \mathrm{ScC}_{2}$-lager.

Ett huvudintresse i mina projekt har varit sökandet efter lagrade magnetiska material, då detta kan vara av betydelse för till exempel datalagring. Jag har därför syntetiserat flera magnetiska material, där delar av de lager som bygger upp materialet består av magnetiska atomer. Ett exempel är $\left(\mathrm{Mo}_{2 / 3} \mathrm{~Tb}_{1 / 3}\right)_{2} \mathrm{AlC}$, som är en medlem i en hel familj av nya magnetiska material som jag upptäckt, och som jag studerat med avseende på magnetiska egenskaper. 


\section{Preface and acknowledgments}

This thesis is the result of my doctoral study in the Materials Design group in the Thin Film Physics division at Linkoping University. I have been working on the synthesis and characterization of nanolaminated materials for producing 2D materials and for studying magnetism. The project has been funded by the Swedish Research Council (VR), and the Knut and Alice Wallenberg (KAW) Foundation.

I could not have done my doctoral study without the help of my colleagues and friends. First and foremost, I am grateful for my supervisor, Johanna Rosen, for your patient guidance and giving me opportunity to search freely in science. I am grateful for my co-supervisor, Per Persson, for his support and invaluable expertise in microstructure analysis. I would like to thank colleagues in thin film physics division, especially, Martin Dahlqvist, Jun Lu, ChungChuan Lai, Aurelija Mockute, Andrejs Petruhins, Rahele Meshkian, Joseph Halim, Leiqiang Qing, Justinas Palisaitis, Ingemar Persson, and Jie Zhou. I want to also thank my colleagues in Thin Film Physics for your help.

I am very grateful for our collaborators in other universities. In particular, I am grateful for Michel Barsoum, Michael Farle, Thierry Ouisse, Christine Opagiste, El'ad Caspi, and other collaborators.

Family and friends, I'm deeply grateful for your invaluable support. 


\section{Contents}

Synthesis and characterization of two- and three-dimensional nanolaminated carbides .......i

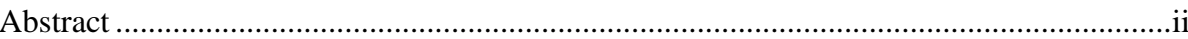

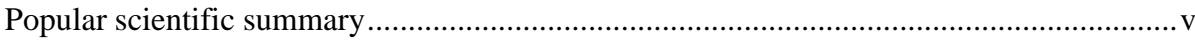

Preface and acknowledgments ...............................................................................

Appended papers and author's contribution .....................................................................

Related but not included papers ..............................................................................

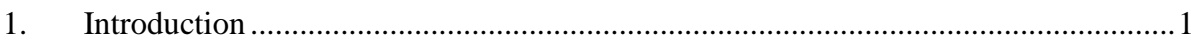

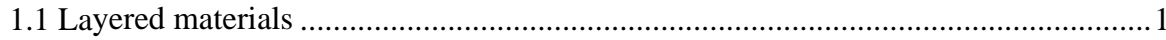

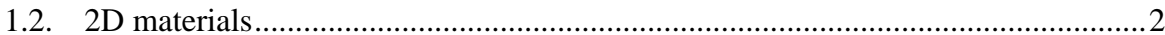

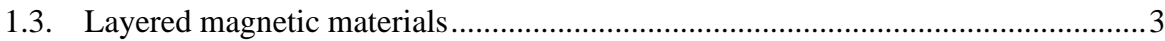

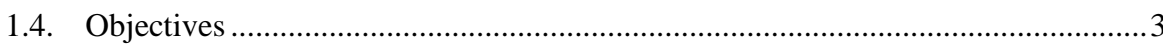

2. MAX phases, other nanolaminated materials, and their two-dimensional derivatives 5

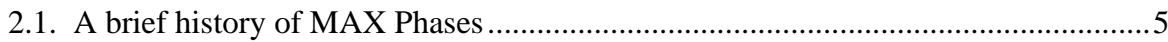

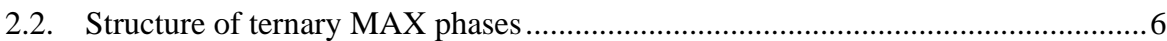

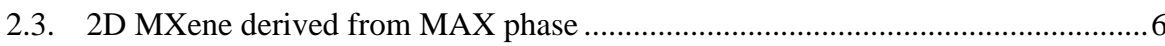

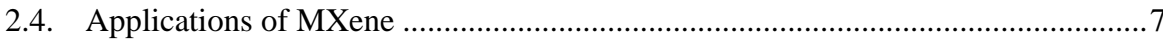

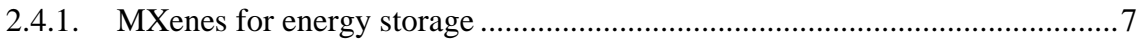

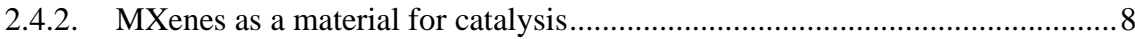

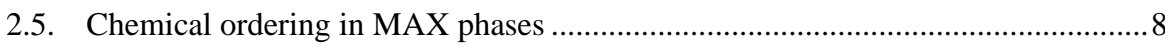

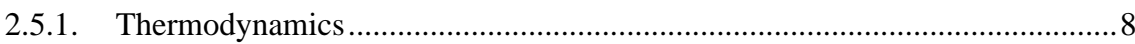

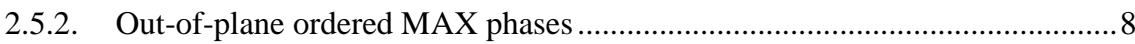

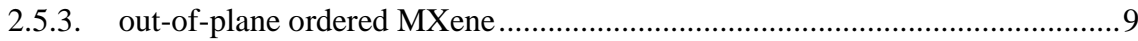

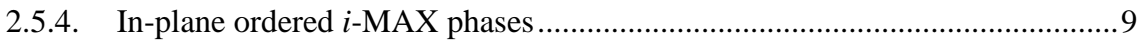

2.5.5. Vacancy-order and chemical order in $i$-MXenes ......................................... 10

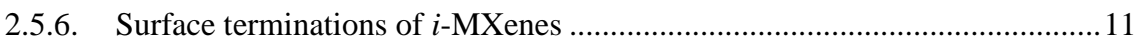

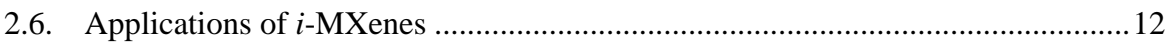

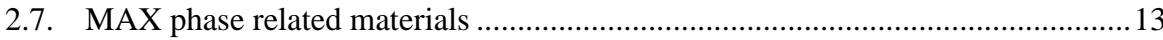

2.7.1. Nanolaminates with Al-C layers ...................................................................... 13 
2.7.2. 2D derivatives of nanolaminates with Al-C layers ..................................... 13

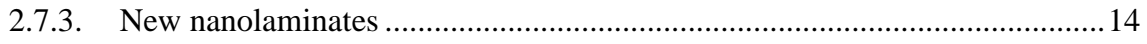

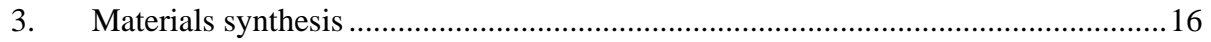

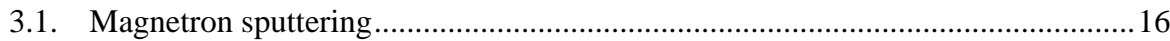

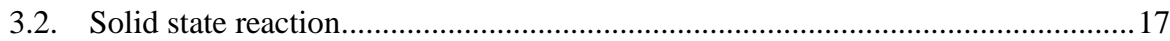

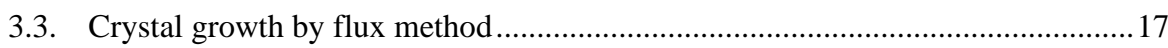

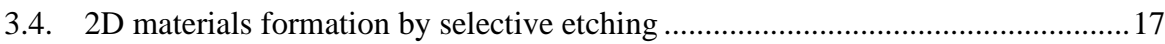

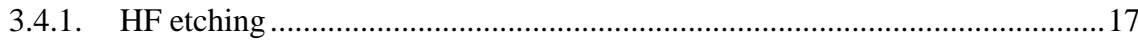

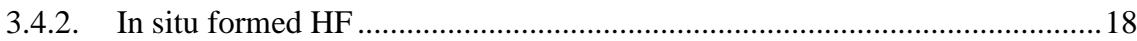

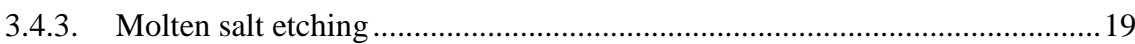

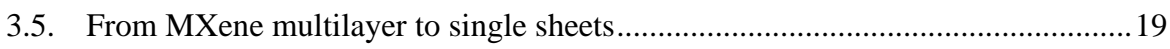

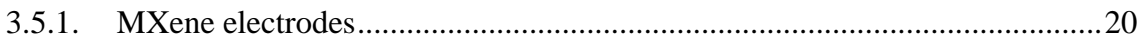

4. Materials characterization: structure and composition...........................................22

4.1. Crystal structure and symmetry operation ..........................................................22

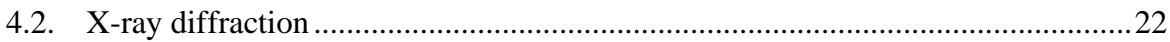

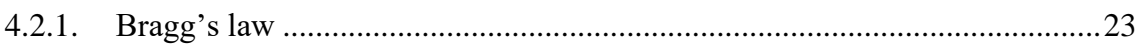

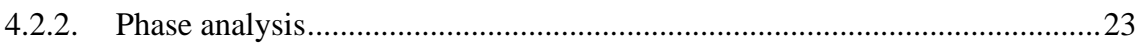

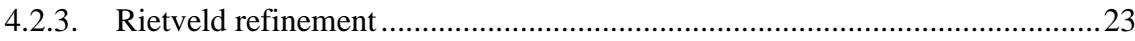

4.3. Transmission electron microscopy (TEM) ….......................................................2

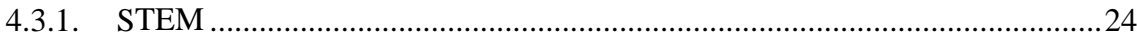

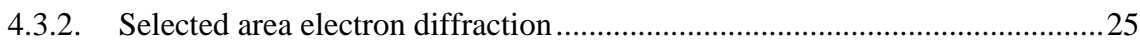

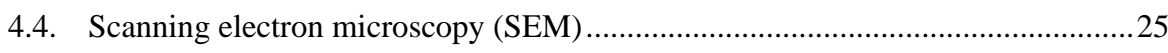

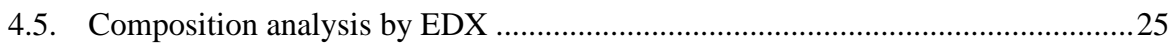

4.6. Neutron diffraction for the study of crystal structure ..........................................26

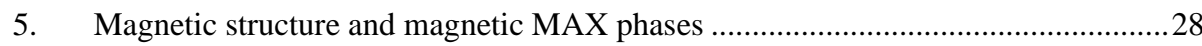

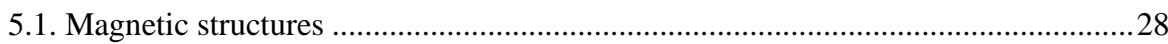

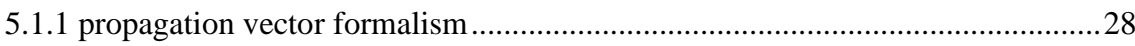

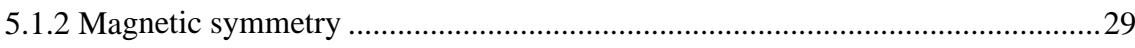

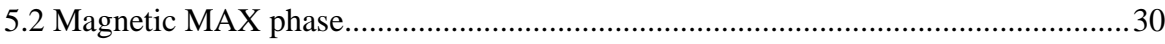

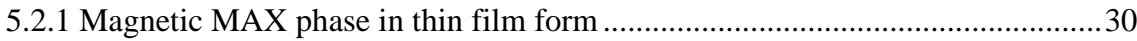

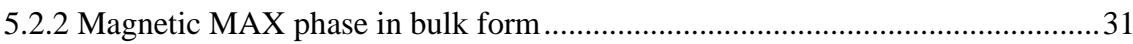

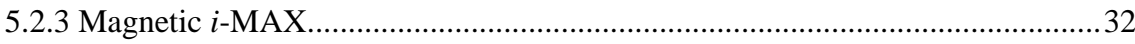




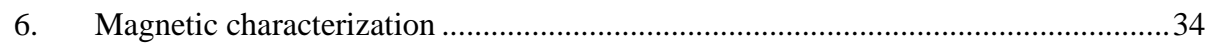

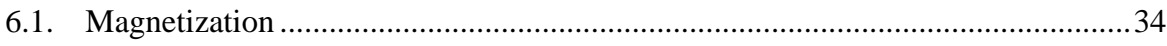

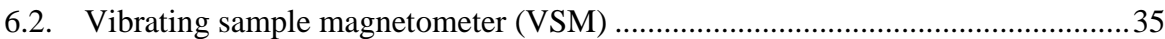

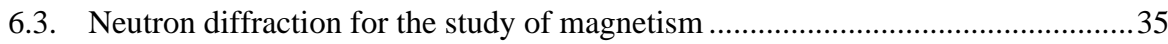

7. Materials characterization: electrochemical characterization ....................................38

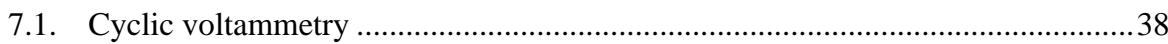

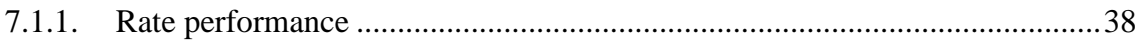

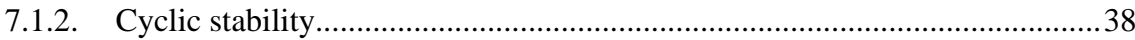

8. Summary of papers and my contribution to the field.................................................40

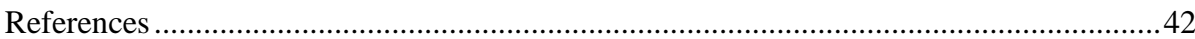




\section{Appended papers and author's contribution}

1. Atomically Layered and Ordered Rare-Earth i-MAX Phases: A New Class of Magnetic Quaternary Compounds. Q Tao, J Lu, M Dahlqvist, A Mockute, S Calder, A Petruhins, R Meshkian, O Rivin, D Potashnikov, EN Caspi, H Shaked, A Hoser, C Opagiste, RM Galera, R Salikhov, U Wiedwald, C Ritter, AR Wildes, B Johansson, L Hultman, M Farle, MW Barsoum, J Rosen. Chemistry of Materials 31 (7), 2476-2485 6, 2019

Contribution: I planned and performed the materials synthesis, part of the characterizations, and wrote the manuscript.

2. Rare-earth (RE) nanolaminates featuring ferromagnetism and mixed-valence states. $\mathbf{Q}$ Tao, T Ouisse, D Pinek, O Chaix-Pluchery, F Wilhelm, A Rogalev, C Opagiste, L Jouffret, A Champagne, J-C Charlier, J Lu, L Hultman, M W Barsoum, J Rosen. Physical Review Materials 2 (11), 114401 2, 2018

Contribution: I planned and performed the materials synthesis, part of the characterizations, and wrote the manuscript.

3. Two-dimensional Mo1.33 C MXene with divacancy ordering prepared from parent 3D laminate with in-plane chemical ordering. Q Tao, M Dahlqvist, J Lu, S Kota, R Meshkian, J Halim, J Palisaitis, L Hultman, MW Barsoum, POÅ Persson, J Rosen. Nature communications 8, 14949 98, 2017

Contribution: I synthesized the materials, and did part of the structural characterizations. I wrote the manuscript.

4. Thin film synthesis and characterization of a chemically ordered magnetic nanolaminate $(\mathrm{V}, \mathrm{Mn})_{3} \mathrm{GaC}_{2}$. Q Tao, R Salikhov, A Mockute, J Lu, M Farle, U Wiedwald, J Rosen. APL Materials 4 (8), 086109 13, 2016

Contribution: I did part of the materials synthesis and structural characterization. I did the magnetization characterization. I wrote the manuscript.

5. Theoretical stability and materials synthesis of a chemically ordered MAX phase, Mo2ScAlC2, and its two-dimensional derivate $\mathrm{Mo}_{2} \mathrm{ScC}_{2}$ MXene. R Meshkian, Q Tao, M Dahlqvist, J Lu, L Hultman, J Rosen. Acta Materialia 125, 476-480 39, 2017

Contribution: I did part of the materials synthesis and structural characterization.

6. Synthesis and structure of a nanolaminated materials $\mathrm{M}_{2} \mathrm{Al}_{2} \mathrm{C}_{3}$ where $\mathrm{M}=\mathrm{Sc}$ and Er. $\mathbf{Q}$ Tao, P Helmer, L Jouffret, M Dahlqvist, J Zhou, Jun Lu, J Rosen. In manuscript

Contribution: I planned and performed the materials synthesis, part of the characterizations, and wrote the manuscript. 


\section{Related but not included papers}

1. Polymer-MXene composite films formed by MXene-facilitated electrochemical polymerization for flexible solid-state microsupercapacitors. L Qin, Q Tao, X Liu, M Fahlman, J Halim, POÅ Persson, J Rosen, F Zhang. Nano Energy 60, 734-742, 2019

2. First-order Raman scattering of rare-earth containing i-MAX single crystals (Mo $2 / 3$ RE 1/3) 2 AlC (RE= Nd, Gd, Dy, Ho, Er) A Champagne, O Chaix-Pluchery, T Ouisse, D Pinek, I Gélard, L Jouffret, M Barbier, F Wilhelm, Q Tao, J Lu, J Rosén, MW Barsoum, J-C Charlier. Physical Review Materials 3 (5), 053609, 2019

3. Stoichiometry and surface structure dependence of hydrogen evolution reaction activity and stability of MoxC MXenes. S Intikhab, V Natu, J Li, Y Li, Q Tao, J Rosen, MW Barsoum, J Snyder. Journal of Catalysis 371, 325-332 1, 2019

4. W-Based Atomic Laminates and Their 2D Derivative W1.33C MXene with Vacancy Ordering. R Meshkian, M Dahlqvist, J Lu, B Wickman, J Halim, J Thörnberg, Q Tao, . S Li, S Intikhab, J Snyder, MW Barsoum, M Yildizhan, J Palisaitis, L Hultman, POA Persson, J Rosen. Advanced Materials 30 (21), 1706409 32, 2018

5. Tailoring Structure, Composition, and Energy Storage Properties of MXenes from Selective Etching of In-Plane, Chemically Ordered MAX Phases. I Persson, A El Ghazaly, Q Tao, J Halim, S Kota, V Darakchieva, J Palisaitis, MW Barsoum, J Rosen, POÅ Persson. Small 14 (17), 1703676 17, 2018

6. Magnetic properties and structural characterization of layered $(\mathrm{Cr} 0.5 \mathrm{Mn} 0.5) 2 \mathrm{AuC}$ synthesized by thermally induced substitutional reaction in $(\mathrm{Cr} 0.5 \mathrm{Mn} 0.5) 2 \mathrm{GaC}$. CC Lai, Q Tao, H Fashandi, U Wiedwald, R Salikhov, M Farle, A Petruhins, J Lu, L Hultman, P Eklund, J Rosen. APL Materials 6 (2), 026104 9, 2018

7. Two-dimensional molybdenum carbide (MXene) with divacancy ordering for brackish and seawater desalination via cation and anion intercalation. P Srimuk, J Halim, J Lee, Q Tao, J Rosen, V Presser. ACS Sustainable Chemistry \& Engineering 6 (3), 37393747 28, 2018 
8. High-Performance Ultrathin Flexible Solid-State Supercapacitors Based on Solution Processable Mo1.33C MXene and PEDOT:PSS. L Qin, Q Tao, AE Ghazaly, J Fernandez - Rodriguez, POA Persson, J Rosen, F Zhang. Advanced Functional Materials 28 (2), 1703808 29, 2018

9. Evidence for ferromagnetic ordering in the MAX phase (Cr0.96Mn0.04)2GeC. O Rivin, EN Caspi, A Pesach, H Shaked, A Hoser, R Georgii, Q Tao, J Rosen, MW Barsoum. Materials Research Letters 5 (7), 465-471 7, 2017

10. Theoretical and Experimental Exploration of a Novel In-Plane Chemically Ordered (Cr2/3M1/3)2AlC i-MAX Phase with $\mathrm{M}=\mathrm{Sc}$ and Y. J Lu, A Thore, R Meshkian, $\mathbf{Q}$ Tao, L Hultman, J Rosen. Crystal Growth \& Design 17 (11), 5704-5711 16, 2017

11. Prediction and synthesis of a family of atomic laminate phases with Kagomé-like and in-plane chemical ordering. M Dahlqvist, J Lu, R Meshkian, Q Tao, L Hultman, J Rosen. Science advances 3 (7), e1700642 38, 2017

12. Theoretical stability and materials synthesis of a chemically ordered MAX phase, Mo2ScAlC2, and its two-dimensional derivate Mo2ScC2 MXene. R Meshkian, Q Tao, M Dahlqvist, J Lu, L Hultman, J Rosen. Acta Materialia 125, 476-480 39, 2017

13. Mo 2 Ga 2 C: a new ternary nanolaminated carbide. C Hu, CC Lai, Q Tao, J Lu, J Halim, L Sun, J Zhang, J Yang, B Anasori, J Wang, Y Sakka, L Hultman, P Eklund, J Rosen, MW Barsoum. Chemical Communications 51 (30), 6560-6563 59, 2015 


\section{Introduction}

Materials have played a very important role in the development of humanity. The progress of human society is defined by the materials that people are using. For example, in the iron age, most of the tools were made of iron. Nowadays, we use all kinds of materials in everyday life. For example, energy storage materials are used in Li-ion batteries, to power, e.g., mobile phones.

As technology advances, we need new materials to meet the ever increasing demands. We will need materials that can store more energy, materials that are stronger and tougher to be more resilient, and materials that can sustain the environment, etc.

I am primarily interested in the synthesis, properties, and applications of a family of layered materials and their two dimensional derivatives, in particular aiming to identify potential material candidates for applications within energy storage or for new magnetic materials.

\subsection{Layered materials}

Layered materials consist of two-dimensional (2D) sheets that are stacked. Their interlayer binding is typically much weaker compared to the intralayer binding. There are many different kinds of layered materials, including oxides, carbides, and chalcogenide, etc. For example, graphite is made of 2D graphene sheets which are held together by weak interlayer van der Waals forces, while the carbon atoms in the plane are strongly covalently bonded. As a result, the physical and mechanical properties are highly anisotropic.

Among the many layered materials, a family of nanolaminated metal carbides, so called MAX phases, have been attracting a lot of attention recently. MAX phases have the general formula $M_{n+1} A X_{n}$, where $M$ is transition metal, $A$ is $A$ group elements, and $X$ is carbon or nitrogen ( $n=1-3)$. MAX phases were first discovered by Nowotny et al. in the 1960s, even though the term "MAX phase" was not used until several decades later, including a set of phases with Ti, Nb, Zr, Hf, V, Mo, Ta, and Cr as M elements[1]. Around 50 MAX phases were identified, and their structures were determined. In the 1990s, Barsoum etc. synthesized $\mathrm{Ti}_{3} \mathrm{SiC}_{2}$ and other MAX phases in dense bulk form and make the mechanical properties characterization possible [2]. They found that MAX phases exhibit a unique combination of merits including machinable, oxidation resistance, high electrical and thermal conductivity, etc. Especially, the fracture toughness, an important parameter which express the ability to resist crack propagation, of MAX phase is much higher than typical structural ceramic like $\mathrm{Al}_{2} \mathrm{O}_{3}$. These merits make them promising candidates for structural components in extreme conditions.

In the last decade, many new MAX phases have been realized. To date, over 150 phases are experimentally synthesized[3]. Figure 1 shows the periodic table of elements, and all elements 
used in MAX phase materials to date, including both pure ternaries and alloys. Notably, M was mainly early transition metal elements before; recently, I introduced the rare earth elements to the MAX phase family.

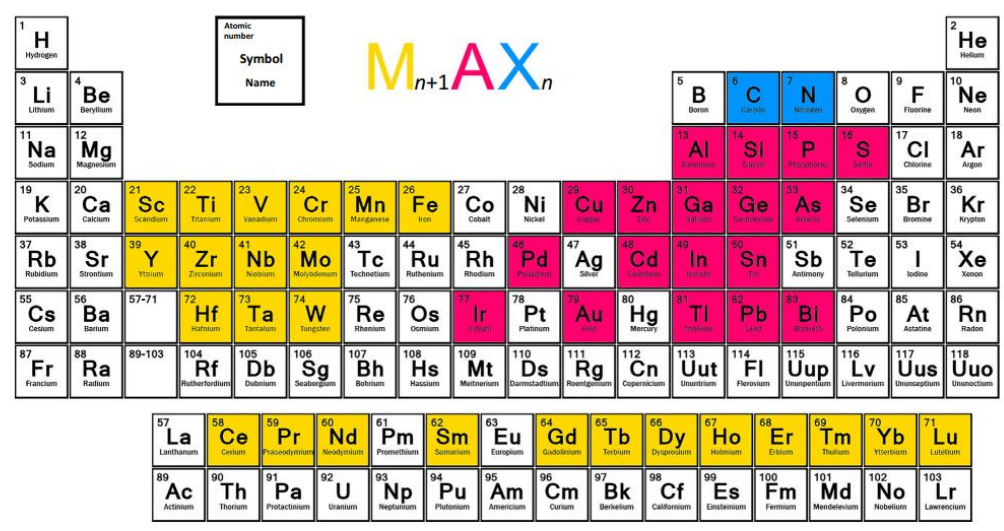

Figure 1. A periodic table showing the chemical diversity of MAX phases[3].

\subsection{D materials}

2D materials are one or a few atom layer thin nanosheets. Before the discovery of graphene, it's generally believed that 2D materials are not allowed by nature due to thermal fluctuation[4]. The mechanical exfoliation of graphite into graphene in 2004 opened up a new world of materials[5]. Graphene has been showing extraordinary properties, such as exotic electronic behaviors[6], the highest thermal conductivity in any materials found to date [7], the strongest materials ever measured [8],etc.

Starting with graphene, the family of 2D materials expands quickly, including metal, semiconductors, and insulators. 2D materials include elemental 2D materials, oxides, carbides, and chalcogenides, etc.

2D materials can also be restacked into heterostructures with various properties [9]. For example, by stacking 2 graphene sheets oriented with a "magic" angle, superconductivity was observed[10]. The behavior of twisted molybdenum diselenide $\left(\mathrm{MoSe}_{2}\right)$ and tungsten diselenide $\left(\mathrm{WSe}_{2}\right)$ heterobilayers can also be tuned by simply changing the twisting angle [11].

MXenes joined the 2D materials family in 2011. Due to their excellent properties, especially as energy storage materials, MXenes have been attracting a lot of attentions. Unlike van der Waals materials, the interlayer bonding in MAX phases is relatively strong. It's not easy to exfoliate these materials directly by mechanical methods. Instead, the 2D transition metal carbides/nitrides, MXenes, can be produced by selectively etching (removing) the A layers 
from the MAX phase. MXenes are very promising in various applications, including, but not being limited to, materials for energy storage and catalyst[12].

\subsection{Layered magnetic materials}

Magnetic materials are used in many applications, such as data storage devices. Especially 2D magnetic materials are an emerging family of materials that are promising for spintronics applications. For example, it was found that ferromagnetism in $\mathrm{CrI}_{3}$ is preserved even down to the monolayer limit [13]. Furthermore, the magnetic behavior of $\mathrm{CrI}_{3}$ nanosheets can be readily controlled by an electric field [14].

I am interested in developing new layered magnetic materials with a potential for exfoliation into 2D materials. The exploration of magnetism in MAX phase was initiated by Ingason, etc[15]. They synthesized several magnetic MAX phases based on $\mathrm{Mn}$, such as $\mathrm{Mn}_{2} \mathrm{GaC}$ [16], and these materials exhibit interesting behavior[17]. Still, my primary goal is to go beyond magnetic materials based on $\mathrm{Cr}$ and $\mathrm{Mn}$.

\subsection{Objectives}

The general objective of this thesis is to experimentally explore new nanolaminated materials, aiming to find materials potentially useful for producing $2 \mathrm{D}$ materials and/or with potentially interesting magnetic behaviors.

By exfoliating layered 3D materials, 2D materials could be formed. We therefore explore new nanolaminated materials that can be potential precursors for $2 \mathrm{D}$ materials through an interlayer interaction that may allow 3D to 2D conversion. When such materials are identified, we try various chemical routes to exfoliate the precursor materials.

Layered 3D magnetic materials are interesting for, e.g., their anisotropic properties. Introducing magnetic elements in such materials, in particular with chemical ordering, will likely induce interesting magnetic characteristics. Consequently, we add magnetic elements to our nanolaminated structures and study their magnetic behaviors.

At last, magnetic 2D materials are envisioned. The explored 3D nanolaminated magnetic materials are potentially useful for the realization of 2D magnetic materials by either targeted etching or mechanical exfoliation.

Altogether, in this thesis, various nanolaminated materials are explored. Their crystal structures are determined, their potential to form 2D materials are studied, and magnetic behavior of selected materials are evaluated. My contribution to the field of MAX phases and related nanolaminates, and their $2 \mathrm{D}$ derivatives, can therefore be summarized into new (magnetic) elements introduced, new phases formed, new 2D derivatives realized, and new (magnetic) characteristics observed and studied. 


\section{MAX phases, other nanolaminated materials, and their two-dimensional derivatives}

\subsection{A brief history of MAX Phases}

The study of MAX phases started in the 1960s by Nowotny, et al. They synthesized about 50 ternary MAX phases and determined their crystal structures. They were called H-phase at the time. They were synthesized by solid state reaction in powder form.

In the 1990s, Barsoum, et. al. prepared fully dense sample of MAX phases, in particular $\mathrm{Ti}_{3} \mathrm{SiC}_{2}$. A fully dense sample makes it possible to characterize their mechanical properties. The materials were found to possess excellent mechanical properties and oxidation resistance, making MAX phases promising for structural materials in extreme environment[18].

Starting from early 2000s, MAX phases in thin film form were also synthesized by sputtering techniques[19]. They can be epitaxially grown on single crystal substrate with exceptionally high crystal quality. Another important progress is the synthesis of magnetic MAX phases in thin film form [17]. For example, $\mathrm{Mn}_{2} \mathrm{GaC}$ has not been synthesized in bulk form, while it can be epitaxially grown on $\mathrm{MgO}$ single crystal substate [16].

In 2011, Naguib et al. found that by selective etching of $\mathrm{Al}$ from $\mathrm{Ti}_{3} \mathrm{AlC}_{2}$, two dimensional $\mathrm{Ti}_{3} \mathrm{C}_{2}$, called MXene, can be produced[20]. MXene has been shown to be excellent for energy storage and in other applications[12].

The discovery of MXenes reignited the interest in MAX phases, e.g. developing new MAX phases as precursors for MXenes. Especially by exploiting chemical ordering, several new MAX phases have been synthesized and their corresponding MXenes have been produced. 


\subsection{Structure of ternary MAX phases}
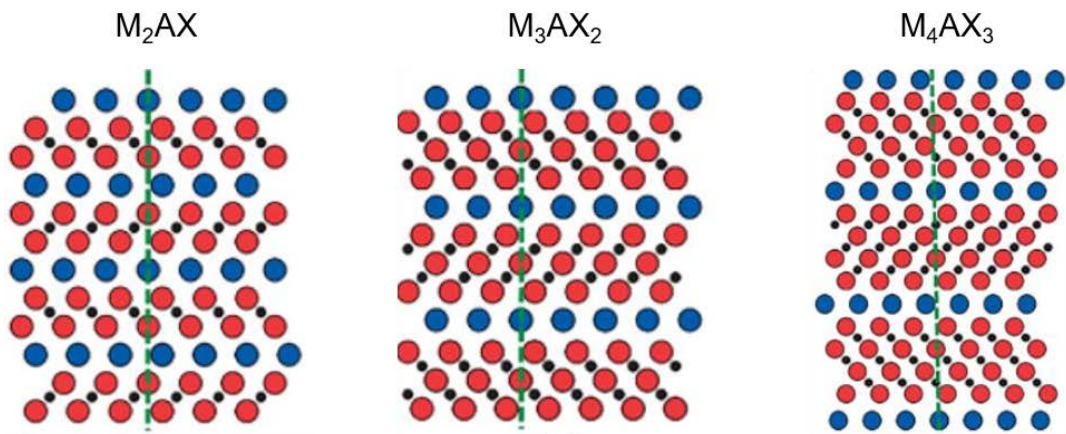

Figure 2. Structure of various ternary MAX phases, (a) $M_{2} A X$, which is commonly referred as 211 phase, (b) $\mathrm{M}_{3} \mathrm{AX}_{2}$ or 312 phase. (c) $\mathrm{M}_{4} \mathrm{AX}_{3}$ or 413 phase. Adapted from [3].

As mentioned earlier, the chemistry of the MAX phase family is very diverse. However, they share the same basic crystal structure, which gives them similar physical and mechanical characteristics. Figure 2 shows the crystal structure of ternary MAX phases. They all consist of transition metal carbide layers interleaved with A layers. Depending on the amount of transition metal layers, they can be categorized into subgroups of 211, 312, and 413 phases. For example, in 211 structure, $\mathrm{M}_{2} \mathrm{X}$ layers are interleaved with A layers.

\subsection{D MXene derived from MAX phase}

In 2011, Naguib et. al. found that by selective etching of $\mathrm{Al}$ from $\mathrm{Ti}_{3} \mathrm{AlC}_{2}, 2 \mathrm{D} \mathrm{Ti}_{3} \mathrm{C}_{2}$ can be produced [20]. As shown in the schematic in Fig. 3a, when $\mathrm{Ti}_{3} \mathrm{AlC}_{2}$ powder is treated with $\mathrm{HF}$, $\mathrm{Al}$ is removed while the strongly bonded $\mathrm{Ti}_{3} \mathrm{C}_{2}$ layers can be preserved. The SEM image in Fig. $3 \mathrm{~b}$ shows the resulting $\mathrm{Ti}_{3} \mathrm{C}_{2}$ after etching. After sonication in water, these layers can be dispersed in water as individual $2 \mathrm{D}$ nanosheets with thickness around $1 \mathrm{~nm}$ and an area up to a few $\mu m^{2}$.

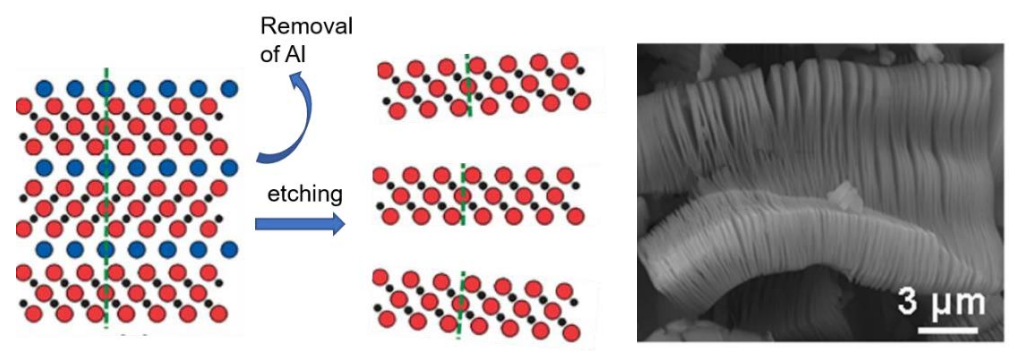

Figure 3. Left: schematic of the etching process. Right: SEM image for $\mathrm{Ti}_{3} \mathrm{AlC}_{2}$ after etching[21].

A similar process has been applied to other MAX phases, including 211, 312, and 413 MAX phases[21]. Various MXenes with different stoichiometry and compositions have been produced. These materials are typically found to be highly conductive and hydrophilic, which 
are important for various applications including energy storage. Similar to the general formula of MAX phases, MXenes can be described by the general formula, $M_{n+1} X_{n} T_{x}$ where $M_{n+1} X_{n}$ follows the corresponding $M_{n+1} A X_{n}$ precursor, $T$ is the surface termination, and $x$ is the number of terminations per formula unit.

After removal of the A layers, the $\mathrm{M}$ surface is terminated with primarily $-\mathrm{F},=\mathrm{O}$, and $-\mathrm{OH}$. It's known that the surface terminations play an important role for the electronic properties and electrochemical properties of MXenes, and it is the terminations that make the MXenes hydrophilic. The control of the surface terminations can be used to tune the properties.

\subsection{Applications of MXene}

There are a great number of publications on the application of MXenes as sensors, for water purification, and for electronic applications, etc. Those interested can read review articles like [12] [22,23]. Below I will briefly introduce the application of MXene for energy storage and as catalysis.

\subsubsection{MXenes for energy storage}

Energy storage materials are very important for various applications, such as in portable devices and as batteries in electric cars. MXenes has been shown to be an excellent material candidate for various energy storage applications such as for supercapacitor and Li-ion batteries.
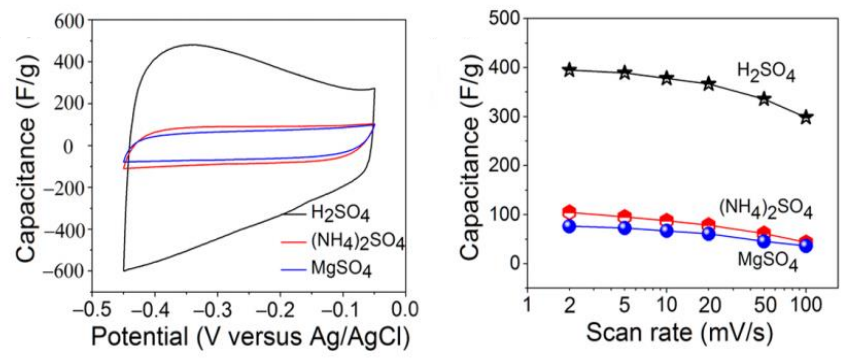

Figure 4 Left: Typical EDL capacitance (red and blue curve) compared to pseudocapacitance (black curve). Right: capacitance at different scan rate. The curve was adapted from Ref: [24]

Electric double layer capacitance (EDL) is only depending on the surface area of the electrode, giving a rectangular shaped $\mathrm{CV}$ curve as shown in the red and blue curves in Figure 4 (left). When an acidic electrolyte $\mathrm{H}_{2} \mathrm{SO}_{4}$ is used, the capacitance is the sum of the contribution from redox capacitance and EDL capacitance. As shown in the figure, the CV curve deviate from the rectangular shape due to the contribution of the Faradaic reaction $\mathrm{M}^{\mathrm{n}+}-\mathrm{O}+\mathrm{H}^{+} \mathrm{e}^{-}=$ $\mathrm{M}^{(\mathrm{n}-1)+}-\mathrm{OH}$ [24]. Due to the redox capacitance, the capacitance is greatly enhanced compared to the EDL capacitance alone.

Owing to the Pseudocapacitive behavior, MXenes have been tested for various forms of supercapacitor electrodes [25-28]. Typically, the gravimetric capacitance can reach around 400 
$\mathrm{F} / \mathrm{g}$ and the volumetric capacitance can reach around $1500 \mathrm{~F} / \mathrm{cm}^{3}$. Both values are among the highest for any electrode material. The performance can be further enhanced by modifying the stacking [29] and by making a composite by adding carbon nanotube or polymers [30].

\subsubsection{MXenes as a material for catalysis}

Catalysts are wildly used in the industry to increase the rate of chemical reactions. For example, hydrogen is an important reagent in the industry. It's mainly produced from water by hydrogen evolution reaction (HER). This reaction relies on Pt as catalyst, which is expensive. It's highly motivated to search for efficient catalysts based on cheaper alternatives, like transition metal compounds.

MXene can be used as catalyst for various reactions, as demonstrated by initial investigations reported recently. For example, $\mathrm{Mo}_{2} \mathrm{C}$ MXene can be used as catalyst for hydrogen evolution reaction[31]. W-based MXene have also been found to be an efficient catalyst for hydrogen evolution reaction[32]. Though the efficiency of MXene is not comparable with $\mathrm{Pt}$, it has a high tuning potential and may be possible to further improve owing to the rich chemistry [33]. MXene can also be used as catalyst for other important reactions. For example, $\mathrm{Ti}_{3} \mathrm{C}_{2} \mathrm{MXene}$ can be used as efficient catalyst for $\mathrm{N}_{2}$ fixation[34].

\subsection{Chemical ordering in MAX phases}

\subsubsection{Thermodynamics}

The state of a system is determined by Gibbs free energy, $\mathrm{G}=\mathrm{H}-\mathrm{TS}$, where $\mathrm{H}$ is the enthalpy, $\mathrm{T}$ is the temperature, and $\mathrm{S}$ is the entropy. Entropy is associated with the degree of disorder in a system. At high temperature, $\mathrm{T} \gg 0 \mathrm{~K}$, disordered state is typically favored in order to minimize the free energy. At low temperature, an ordered state can correspondingly be favored.

Thermodynamic applies to the ordering or disordering in materials. Upon thermodynamical equilibrium, the constituting atoms will be arranged in its lowest energy state. Here, we are interested in the chemical ordering in MAX phase alloys, when the M represents more than one element. Below we will discuss two examples of ordered structures, out-of-plane ordering and in-plane ordering.

\subsubsection{Out-of-plane ordered MAX phases}

In 312 MAX phases, there are two metal sites, $2 a$ and $4 f$ Wyckoff sites. Liu et al found that in $\left(\mathrm{Cr}_{2 / 3} \mathrm{Ti}_{1 / 3}\right)_{3} \mathrm{AlC}_{2}, \mathrm{Cr}$ are preferably located at the $4 f$ sites and $\mathrm{Ti}$ at the $4 a$ sites, instead of forming a random solid solution[35]. Figure 5 shows a schematic of the structure of $\left(\mathrm{Cr}_{2 / 3} \mathrm{Ti}_{1 / 3}\right)_{3} \mathrm{AlC}_{2}$. The structure consists of $\mathrm{Cr}-\mathrm{C}-\mathrm{Ti}-\mathrm{C}-\mathrm{Cr}$ layers in the M-C layers. As the two $\mathrm{M}$ elements are ordered along the $c$ axis, they are called out-of-plane ordered MAX phases. Since the observations made for $\left(\mathrm{Cr}_{2 / 3} \mathrm{Ti}_{1 / 3}\right)_{3} \mathrm{AlC}_{2}$, several new ordered phases have been synthesized, including $\mathrm{Mo}_{2} \mathrm{TiAlC}_{2}$ [36] and $(\mathrm{CrV})_{3} \mathrm{AlC}_{2}$ [37], etc. Theoretical studies on outof-plane ordered MAX phases suggests that the ordering was formed due to the breaking of unfavorable stackings and occupation of antibonding orbitals [38]. 
In paper 5, we synthesized another MAX phase with out-of-plane ordering, $\mathrm{Mo}_{2} \mathrm{ScAlC}_{2}$. Mo preferably occupy the $4 f$ sites and Sc occupy the $4 a$ sites.

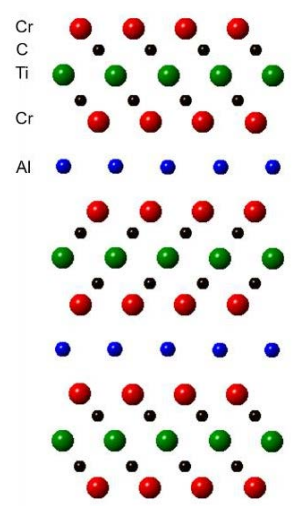

Figure 5. Schematics of out-of-plane ordered $\left(\mathrm{Cr}_{2 / 3} \mathrm{Ti}_{1 / 3}\right)_{3} \mathrm{AlC}_{2}$. Cr atoms are located at $4 f$ site while Ti are located at $2 a$ site.

\subsection{3. out-of-plane ordered MXene}

$\mathrm{Mo}_{2} \mathrm{TiAlC}_{2}$

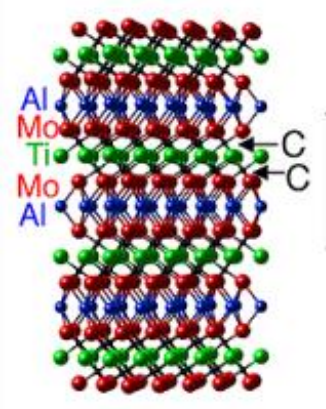

$\mathrm{Mo}_{2} \mathrm{TiC}_{2}$

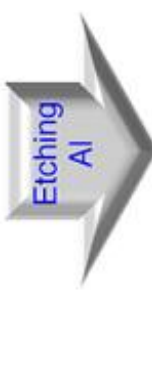

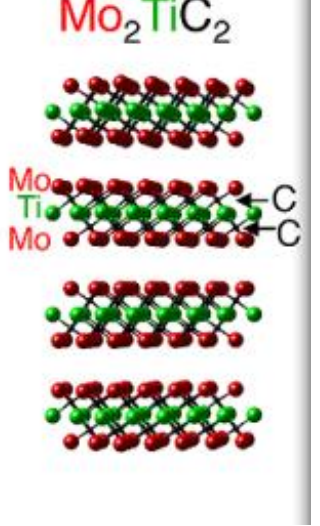

Figure 6. Schematics of out-of-plane ordered $\left(\mathrm{Mo}_{2 / 3} \mathrm{Ti}_{1 / 3}\right)_{3} \mathrm{AlC}_{2}$ and its transformation to ordered $\mathrm{Mo}_{2} \mathrm{TiC}_{2} \mathrm{MXene[39].}$

When an out-of-plane ordered MAX phase is etched, the two elements in the produced MXene is also ordered. Figure 6 shows the schematic of the transformation of the out-of-plane ordered MAX phase to its corresponding MXene [39].

\subsubsection{In-plane ordered $i$-MAX phases}

In contrast to out-of-plane ordering, the two M elements can also be ordered in the transition metal plane, i.e. be in-plane ordered. Figure 7 shows a schematic of the structure of the first synthesized so called $i$-MAX phase $\left(\mathrm{Mo}_{2 / 3} \mathrm{Sc}_{1 / 3}\right)_{2} \mathrm{AlC}$. Similar to other ternary $211 \mathrm{MAX}$ phases, $\left(\mathrm{Mo}_{2 / 3} \mathrm{Sc}_{1 / 3}\right)_{2} \mathrm{AlC}$ consists of metal carbide layers $\left[\left(\mathrm{Mo}_{2 / 3} \mathrm{Sc}_{1 / 3}\right)_{2} \mathrm{C}\right]$ interleaved with an $\mathrm{Al}$ layer. 
The metal carbide layers, however, consist of alternating two columns of Mo and one column of Sc. The structure of $i$-MAX phases is described in detail in paper 1 and paper 3 .

Neither $\mathrm{Mo}_{2} \mathrm{AlC}$ nor $\mathrm{Sc}_{2} \mathrm{AlC}$ is stable. The in-plane chemical ordering of Mo and Sc seems to have stabilized the structure. The same mechanism may work for other combinations as well. Indeed, we have explored the compositional space of many different quaternary phases with DFT, to assess the stability of possible new phases with $i$-MAX structure and experimentally verify the predicted phases. Soon after the first discovery, a family of $i$-MAX phases was established. Dahlqvist et al. reported the prediction and synthesis of $\left(\mathrm{Mo}_{2 / 3} \mathrm{Y}_{1 / 3}\right)_{2} \mathrm{AlC}$ and $\left(\mathrm{V}_{2 / 3} \mathrm{Zr}_{1 / 3}\right)_{2} \mathrm{AlC}[40]$. Lu et al. reported $\left(\mathrm{Cr}_{2 / 3} \mathrm{Sc}_{1 / 3}\right)_{2} \mathrm{AlC}$ and $\left(\mathrm{Cr}_{2 / 3} \mathrm{Y}_{1 / 3}\right)_{2} \mathrm{AlC}$ [41]. Meshkian et al. reported $\left(\mathrm{W}_{2 / 3} \mathrm{Sc}_{1 / 3}\right)_{2} \mathrm{AlC}$ and $\left(\mathrm{W}_{2 / 3} \mathrm{Y}_{1 / 3}\right)_{2} \mathrm{AlC}[42]$, etc.

Although only the $(C 2 / c)$ structure is found for the first $i$-MAX member, $\left(\mathrm{Mo}_{2 / 3} \mathrm{Sc}_{1 / 3}\right)_{2} \mathrm{AlC}$, the proposed degenerate orthorhombic $(\mathrm{Cmcm})$ structure has been experimentally found for other $i$-MAX phases. $\left(\mathrm{Cr}_{2 / 3} \mathrm{Y}_{1 / 3}\right)_{2} \mathrm{AlC}$ crystalizes in the $(\mathrm{Cmcm})$ structure, and both the $(\mathrm{C} 2 / \mathrm{c})$ and the $(\mathrm{Cmcm})$ structures are found in $\left(\mathrm{W}_{2 / 3} \mathrm{Y}_{1 / 3}\right)_{2} \mathrm{AlC}$ and in $\left(\mathrm{Cr}_{2 / 3} \mathrm{Sc}_{1 / 3}\right)_{2} \mathrm{AlC}$.

Based on theoretical evaluation, several criteria have been suggested for the formation of $i$ MAX phases: (1) a 2:1 ratio for the $\mathrm{M}^{1}: \mathrm{M}^{2}$ elements, (2) a large size difference, $\mathrm{M}^{1}: \mathrm{M}^{2}>0.2$ $\AA$, (3) an electron population of ideally bonding orbital only, and (4) a smaller size of A is favorable [43]. With an improved understanding of the formation and large scale theoretical survey, it's foreseeable that more $i$-MAX phases will be synthesized.

\subsubsection{Vacancy-order and chemical order in $i$-MXenes}

As most of the $i$-MAX phases are Al-based, it was from the start highly motivated to attempt their conversion into 2D MXenes. It was found that $\mathrm{Mo}_{1.33} \mathrm{C}$ MXene with divacancy ordering can be achieved by selectively etching $\mathrm{Al}$ as well as $\mathrm{Sc}$ from $\left(\mathrm{Mo}_{2 / 3} \mathrm{Sc}_{1 / 3}\right)_{2} \mathrm{AlC}$ [26]. After etching in either $\mathrm{HF}$ or $\mathrm{LiF} / \mathrm{HCl}, \mathrm{Sc}$ and $\mathrm{Al}$ were removed, while the $\mathrm{Mo}_{1.33} \mathrm{C}$ layers were preserved. The schematic in Figure 7 shows the formation of ordered divacancies. Usually, for traditional MAX phases, only the A layers are removed after etching, while the strongly bonded metal carbide layers are preserved. In the case of $\left(\mathrm{Mo}_{2 / 3} \mathrm{Sc}_{1 / 3}\right)_{2} \mathrm{AlC}$, and possibly due to a weaker bonding of Sc to the rest of the M-layer, Sc is also removed after etching.
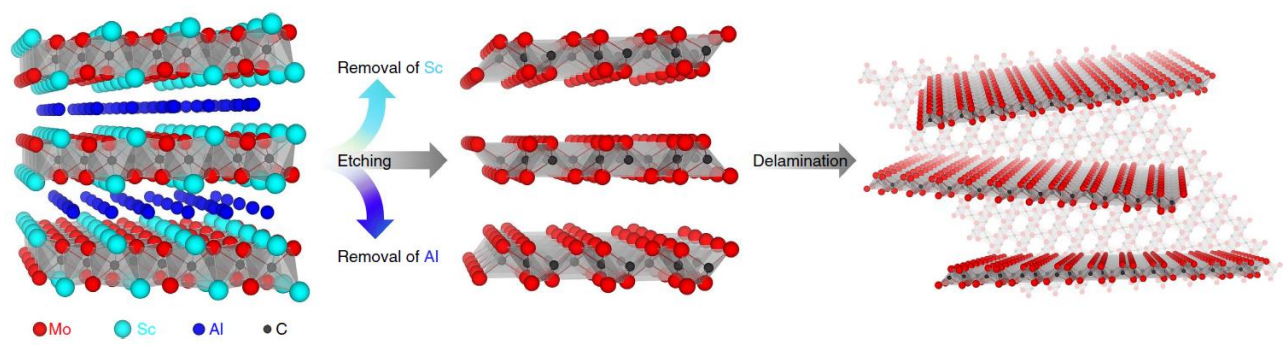

Figure 7. Schematic $\left(\mathrm{Mo}_{2 / 3} \mathrm{Sc}_{1 / 3}\right)_{2} \mathrm{AlC}$ before etching, after etching, and after delamination. 
a

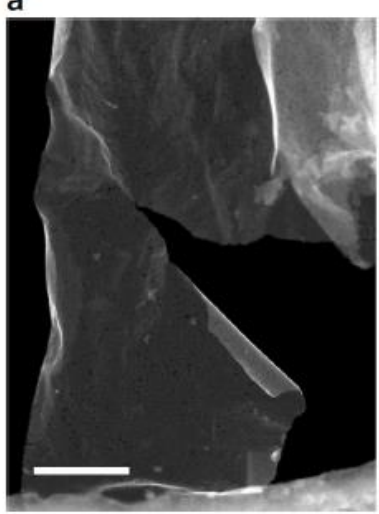

b

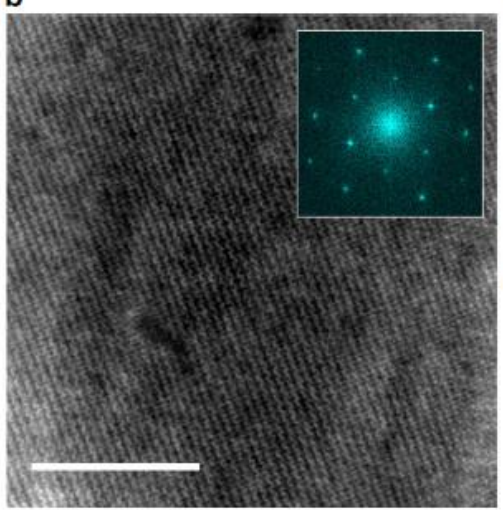

C

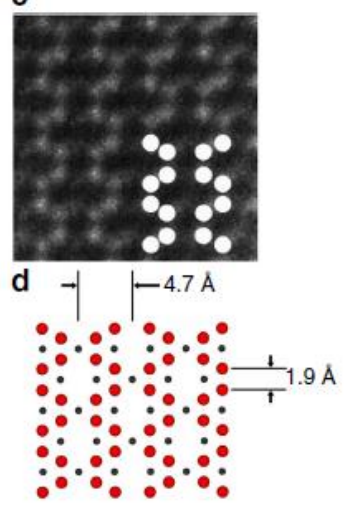

Figure 8. Top view of STEM of single layer Mo1.33C MXene.

The structure of the resulting $\mathrm{Mo}_{1.33} \mathrm{C}$ MXene can be directly visualized by atomic resolution STEM imaging on a single layer. The experimentally obtained STEM image in Figure 8 agrees strikingly well with the simulated structure of a parent MAX phase excluding the $\mathrm{Sc}$ and $\mathrm{Al}$ atoms, as shown in Fig. 8d. A detailed description of the structure of an $i$-MXene can be found in ref [44].

Selective etching of the chemically ordered laminates can also be applied to other $i$-MAX phases. Selective etching of $\mathrm{Sc}$ and $\mathrm{Al}$ from $\left(\mathrm{W}_{2 / 3} \mathrm{Sc}_{1 / 3}\right)_{2} \mathrm{AlC}$ results in $\mathrm{W}_{1.33} \mathrm{C}$ MXene. Selective etching of $\mathrm{Y}$ and $\mathrm{Al}$ from $\left(\mathrm{W}_{2 / 3} \mathrm{Y}_{1 / 3}\right)_{2} \mathrm{AlC}$ and $\left(\mathrm{Mo}_{2 / 3} \mathrm{Y}_{1 / 3}\right)_{2} \mathrm{AlC}$ result in $\mathrm{W}_{1.33} \mathrm{C}$ MXene and $\mathrm{Mo}_{1.33} \mathrm{C}$ MXene, respectively.

The additional diversity and high potential of these materials are evident from our concept of "targeted etching", which is detailing the chemical etching procedures to obtain either a vacancy MXene, or a chemically ordered MXene from the same parent material, as shown for $\left(\mathrm{Mo}_{2 / 3} \mathrm{Y}_{1 / 3}\right)_{2} \mathrm{AlC}$.

\subsubsection{Surface terminations of $i-M X e n e s$}

Similar to other MXenes, $\mathrm{Mo}_{1.33} \mathrm{C}$ i-MXene is also terminated with $\mathrm{F}$, $\mathrm{O}$, and $\mathrm{OH}$, with a chemical formula of $\mathrm{Mo}_{1.2} \mathrm{CO}_{0.7}(\mathrm{OH})_{0.5} \mathrm{~F}_{1.1} \cdot 0.4 \mathrm{H}_{2} \mathrm{O}_{\text {ads }}$ as determined from XPS analysis. The primary termination is $-\mathrm{F}$, in contrast to the primarily $\mathrm{O}$-terminated $\mathrm{Mo}_{2} \mathrm{C}$ (which has no vacancies in its ideal form).

Lind et al. studied the electronic properties of Mo-based MXenes by first-principles calculations[44]. It was found that the preferred termination sites of $i$-MXene are located at the bridge sites between Mo atoms, defined as E site. The Mo-based MXene without ordered vacancies, i.e. $\mathrm{Mo}_{2} \mathrm{C}$ MXene, tends to be terminated on $\mathrm{A} / \mathrm{B}$ site, where $\mathrm{A}$ is located centered between three Mo atoms and directly above a Mo atom in the opposite layer and B is located above the $\mathrm{C}$ atoms. The electronic structure was also calculated for different combinations of terminations. A concentration of approximately 10:2F (close to the experimentally found 
formula) leads to the highest charge density compared to various other termination configurations/concentrations.

\subsection{Applications of $i$-MXenes}

Traditional MXenes have been shown to be promising materials for various applications, including as electrode material for energy storage, as catalyst, and for sensors, etc.[12] Even though the discovery of $i$-MXene is only very recent, we have shown that $i$-MXenes are promising for several applications.

Mo1.33 C $i$-MXene shows indications for being an excellent electrode material for supercapacitor applications.[45,46] Figure 9a shows the cyclic voltammograms (CV) at different scan rates. A capacitance up to $1153 \mathrm{~F} \mathrm{~cm}^{-3}\left(339 \mathrm{~F} \mathrm{~g} \mathrm{~g}^{-1}\right)$ can be achieved with a $3 \mu \mathrm{m}$ thick electrode. The ultrahigh capacitance is attributed to the pseudocapacitive mechanism and excellent electronic conductivity. Several broad peaks are present, leading to large deviations from the rectangular shape expected from double-layer capacitance alone. Quantification of the capacitive contribution to the total current was analyzed using the Wang et al. approach[47]. The capacitive contribution to the total current increases from $45 \%$ at $2 \mathrm{mV} \mathrm{s}^{-1}$ to $79 \%$ at $500 \mathrm{mV}$ $\mathrm{s}^{-1}$. Thus, we conclude that pseudocapacitance is the major operative mechanism herein as postulated for other MXenes[48].

It should be noted that the capacitance of the $\mathrm{Mo}_{1.33} \mathrm{C} i$-MXene reached a record value already at the first time published, in the initial evaluation. In comparison, the first report on $\mathrm{Ti}_{3} \mathrm{C}_{2}$ MXene reached $300 \mathrm{~F} \mathrm{~cm}^{-3}$. It typically takes around a year or more to optimize the precursor MAX phase, the etching conditions, the surface terminations, and the structure of the assembled MXene, to increase the capacitance. For example, a more recent study shows a capacitance up to $1500 \mathrm{~F} \mathrm{~cm}^{-3}$ for a $\mathrm{Ti}_{3} \mathrm{C}_{2} / \mathrm{H}_{2} \mathrm{SO}_{4}$ hydrogel.[29]. We correspondingly expect that $\mathrm{Mo}_{1.33} \mathrm{C} i$-MXene may outperform $\mathrm{Ti}_{3} \mathrm{C}_{2} \mathrm{MXene}$ in the near future.

Utilizing the excellent pseudocapacitive property, $\mathrm{Mo}_{1.33} \mathrm{C} i$-MXene was found to be an effective material for removing cations and anions[49], and capacitive material for a flexible supercapacitor [46]. A promising desalination performance of $15 \mathrm{mg} / \mathrm{g}$ with high charge efficiency up to $95 \%$ was reported for binder-free $\mathrm{Mo}_{1.33} \mathrm{C} i$-MXene electrodes. Notably, the compatibility of MXene for desalination of high concentration saline solution suggests new application areas, such as the generation of drinking water from seawater. Qin et al. reported the solution processed fabrication of a $\mathrm{Mo}_{1.33} \mathrm{C} i$-MXene/conducting polymer composite and excellent electrochemical properties of flexible devices made from the composite [46]. Using a limited amount of conducting polymer, i.e. MXene:Polymer=10:1 in mass ratio, $1310 \mathrm{~F} \mathrm{~cm}^{-}$

${ }^{3}$ was achieved. The enhanced capacitance compared to MXene alone $\left(\sim 1150 \mathrm{~F} \mathrm{~cm}^{-3}\right)$ is likely due to increased spacing between the MXene layers. It is also suggested that the coupling between the negatively charged MXene and positively charged PEDOT may contribute to the enhanced performance, similar to the mechanism proposed for PEDOT:PSS[50]. 

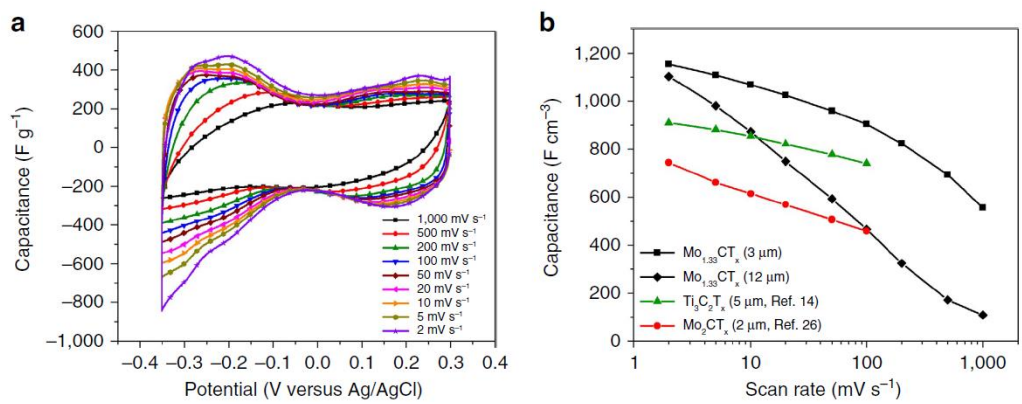

Fig 9. a. Cyclic Voltammetry of $\mathrm{Mo}_{1.33} \mathrm{C} i$-MXene at different scan rate. b. Capacitance value at different scan rate, comparing to other reported MXene.

\subsection{MAX phase related materials}

\subsubsection{Nanolaminates with Al-C layers}

As described in the previous sections, a MAX phase consists of metal carbide layers interleaved with A group elements. Another family of nanolaminated materials have a closely related structure with MAX phases. These materials are composed of metal carbide layers which are interleaved with Al-C layers instead of pure A-group elements [51]. Figure 10 shows a typical example of such material, $\mathrm{Zr}_{3} \mathrm{Al}_{3} \mathrm{C}_{5}$. The structure consists of alternating layers of $\mathrm{Zr}_{3} \mathrm{C}_{2}$ and $\mathrm{Al}_{3} \mathrm{C}_{3}$. As the structure resembles to that of MAX phase, these materials share some characteristics of MAX phases [52].

\subsection{2. $2 \mathrm{D}$ derivatives of nanolaminates with $\mathrm{Al}-\mathrm{C}$ layers}

2D materials formation have also been achieved by selective etching of nanolaminates with Al-C layers. Zhou et. al. produced $\mathrm{Zr}_{3} \mathrm{C}_{2}$ MXene by selective etching of the Al-C layers from $\mathrm{Zr}_{3} \mathrm{Al}_{3} \mathrm{C}_{5}$ as shown in the schematic in Figure 10 [53]. Similarly, $\mathrm{Hf}_{3} \mathrm{C}_{2}$ MXene was produced from $\mathrm{Hf}_{3}[\mathrm{Al}(\mathrm{Si})]_{4} \mathrm{C}_{6}$ [54]. It's worth mentioning that $\mathrm{Zr}$ or Hf based MXene had not been realized before due to lack of suitable MAX phase as precursor. Thus, selective etching of MAX phase related materials is a promising route to explore new MXenes. 


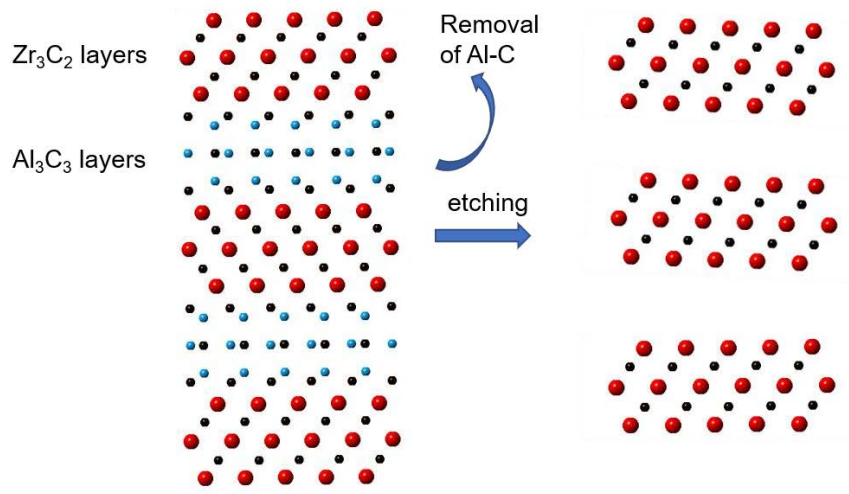

Figure 10 schematic structure of $\mathrm{Zr}_{3} \mathrm{Al}_{3} \mathrm{C}_{5}$ and its etching process.

\subsubsection{New nanolaminates}

Inspired by the conversion of MAX related materials to their 2D counterparts, we also explored new nanolaminates beyond MAX phases.

One example of a new nanolaminate is $\mathrm{Sc}_{2} \mathrm{Al}_{2} \mathrm{C}_{3}$. Figure 11 shows the STEM images and corresponding schematic structure of $\mathrm{Sc}_{2} \mathrm{Al}_{2} \mathrm{C}_{3}$. The structure consists of $\mathrm{Sc}_{2} \mathrm{C}$ layers interleaved with Al-C layers. It's another example of the above mentioned nanolaminates with Al-C layers.

These materials have only been synthesized recently. Their properties remain to be characterized.
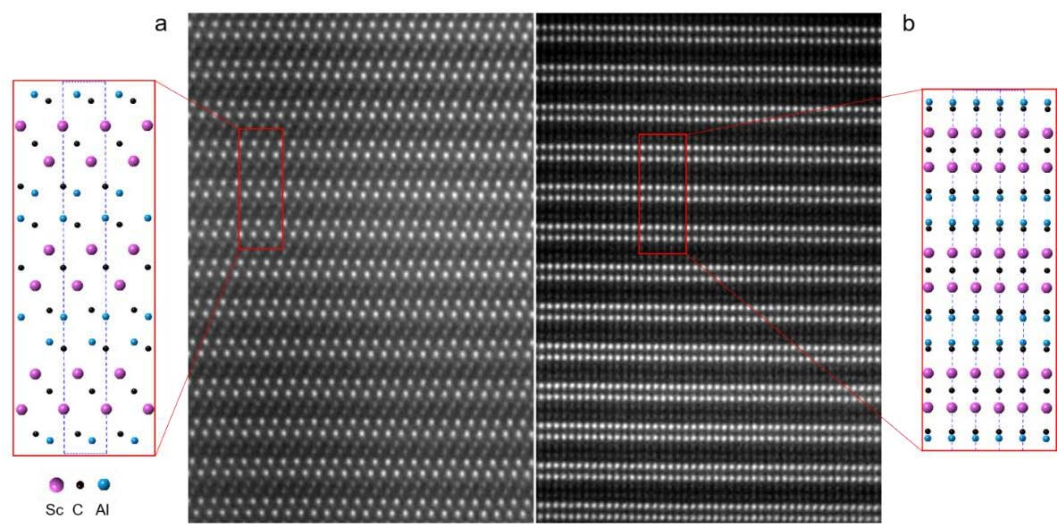

Figure 11. crystal structure and STEM images of $\mathrm{Sc}_{2} \mathrm{Al}_{2} \mathrm{C}_{3}$. 


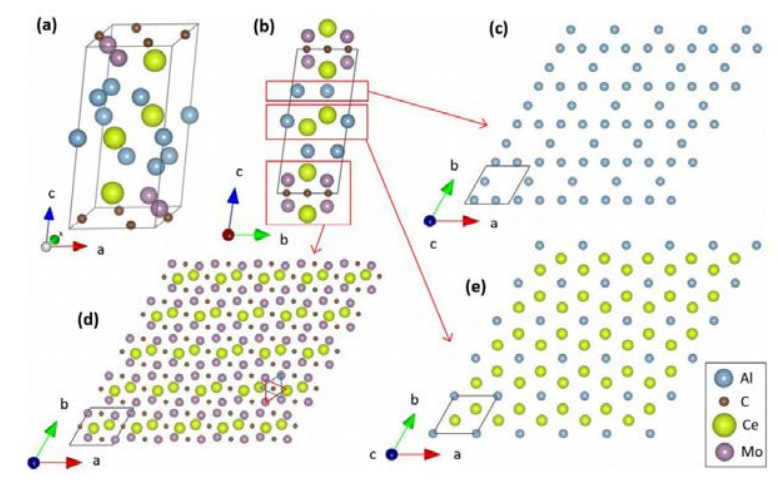

Figure 12. crystal structure of $\mathrm{Mo}_{4} \mathrm{Ce}_{4} \mathrm{Al}_{7} \mathrm{C}_{3}$.

Another example of MAX phase related nanolaminates is $\mathrm{Mo}_{4} \mathrm{Ce}_{4} \mathrm{Al}_{7} \mathrm{C}_{3}$. The structure consists of $\left(\mathrm{Mo}_{2 / 3} \mathrm{Ce}_{1 / 3}\right)_{2} \mathrm{C}$ layers interleaved with three $\mathrm{Al}-\mathrm{Ce}$ layers as shown in Fig. 12. In analogy with a MAX phase, the formula can be rewritten as $\left(\mathrm{Mo}_{2 / 3} \mathrm{Ce}_{1 / 3}\right)_{2}\left(\mathrm{Al}_{7 / 3} \mathrm{Ce}_{2 / 3}\right) \mathrm{C}$. In other words, it can be viewed as a MAX phase with three A layers, which is similar with $\mathrm{Mo}_{2} \mathrm{Ga}_{2} \mathrm{C}$ with two A layers. It will be further discussed in Paper 2.

It's worth mentioning that mechanical exfoliation of $\mathrm{Mo}_{4} \mathrm{Ce}_{4} \mathrm{Al}_{7} \mathrm{C}_{3}$ into few layer $2 \mathrm{D}$ material was recently reported[55]. This is also the first successful attempt of mechanical exfoliation of a MAX phase or a related material, in contrast to the conventional chemical exfoliation route. This is interesting as the interlayer bonding in this laminate is much stronger than that of van der Waals materials. It would be interesting to investigate if the magnetic order is preserved down to the monolayer limit. 


\section{Materials synthesis}

In this chapter, synthesis methods involved in this thesis are described. The nanolaminated materials studied involve magnetron sputtering, high temperature solid state reaction, or high temperature solution growth. 2D materials are produced by exfoliation of nanolaminated materials.

\subsection{Magnetron sputtering}

Magnetron sputtering is a widely used technique to fabricate thin films. When a target is bombarded by energetic particles, very often $\mathrm{Ar}^{+}$, particles can be ejected from the target, and some of them can be deposited on to the substrate and form a thin film.
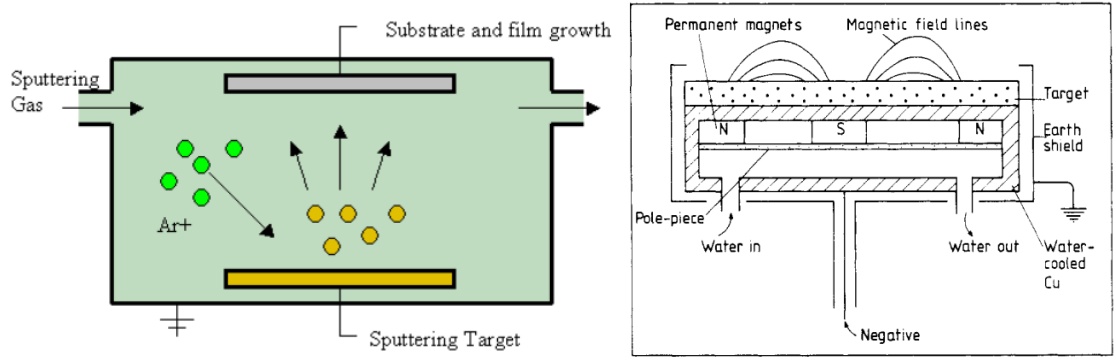

Figure 13 schematic of the sputtering process and magnetron [56].

After pumping down the chamber to ultrahigh vacuum, a low pressure gas, typically Ar, is introduced into the chamber. By applying a high voltage between the anode and cathode, plasma can be ignited. The plasma consists of $\mathrm{Ar}^{+}$and free electron. In the presence of electric field, $\mathrm{Ar}^{+}$will move towards sputtering target and bombard the target material.

Magnetrons are generally used to enhance the ionization efficiency and maintain the plasma. With the arrangement of permanent magnet, electrons are trapped around the target, so that the plasma is maintained around the target.

We usually use single crystal substrate as template for the film growth. The $a$ lattice parameter of MAX phases is around $3 \AA$. To minimize the lattice mismatch, $\mathrm{Al}_{2} \mathrm{O}_{3}(001)$ and $\mathrm{MgO}$ (111) substrate are frequently used. For the deposition of MAX phases, we usually use three elemental targets. By controlling the deposition rate of each target, stoichiometry in the deposited film can be precisely controlled. Typically, we deposit at temperature around $500{ }^{\circ} \mathrm{C}$. In comparison, synthesis of MAX phase in bulk form usually requires temperature above 1000 ${ }^{\circ} \mathrm{C}$. 


\subsection{Solid state reaction}

Solid state reaction is generally considered as the most widely used method for producing polycrystalline solids. It involves the direct reaction of solid starting materials in solid form. This method is simple and straightforward and requires very simple equipment.

For a reaction to happen, thermodynamic and kinetic factor are important. Thermodynamic determines if the reaction will happen, and kinetic determines the rate of the reaction. Most of the studied nanolaminates have a large formation enthalpy, indicating a strong driving force for the formation. However, the kinetic is controlled by the diffusion of the source materials. Very high temperature is required. In the case of $i$-MAXs, usually $1500{ }^{\circ} \mathrm{C}$ is needed to synthesize these materials.

Many of the materials described in this thesis are synthesized by solid state reaction. As an example, below is the procedure for the synthesis of $\left(\mathrm{Mo}_{2 / 3} \mathrm{Sc}_{1 / 3}\right)_{2} \mathrm{AlC}$. Elemental powder of $\mathrm{Mo}, \mathrm{Sc}, \mathrm{Al}$, and graphite are used as raw materials. These powders generally have particle size around 10 microns. They are mixed in an agate mortar manually and placed in an $\mathrm{Al}_{2} \mathrm{O}_{3}$ crucible. They are heated to $1500{ }^{\circ} \mathrm{C}$ and kept at $1500{ }^{\circ} \mathrm{C}$ for 10 hours. After cooling down to room temperature, the sample is slightly sintered. It is then crushed into powder.

\subsection{Crystal growth by flux method}

Single crystals are very useful for the study of materials. Very often, the understanding of material's intrinsic properties is hindered by impurities and defects. High quality single crystal is a prerequisite for various materials characterization techniques.

Flux method is one of the crystal growth methods that has been shown to be successful for MAX phases [57]. With this method, desired substances are dissolved in a solvent (flux), and single crystals are nucleated and grown from the flux. For example, $\mathrm{Cr}_{2} \mathrm{AlC}$ can be grown from $\mathrm{Cr}$-Al melt at $\sim 1500{ }^{\circ} \mathrm{C}$ [57]. They start with a binary $\mathrm{Cr}$-Al melt in a graphite crucible, and graphite crucible is used as carbon source. At high temperature, carbon is dissolved in the melt, and nucleation and growth of $\mathrm{Cr}_{2} \mathrm{AlC}$ occurs. In this case, $\mathrm{Cr}-\mathrm{Al}$ melt is used as flux, which is called self-flux.

\section{4. $2 \mathrm{D}$ materials formation by selective etching}

As described in chapter 2, MAX phase consists of strongly bonded metal carbide layers and A group element layers. To produce $2 \mathrm{D}$ metal carbide, one needs to remove the A layers without while preserve the MX layers. Various methods are developed for the synthesis of 2D transition metal carbide (MXene). The key concept is that the method should be strong enough to extract A layers and at the same time mild enough to maintain a structurally intact MXene. In another words, the etching should be selective.

\subsubsection{HF etching}

$\mathrm{HF}$ is a widely used selective etching agent. For example, it's extensively used in Si-based industry to remove the $\mathrm{SiO}_{2}$ layers on $\mathrm{Si}$. While $\mathrm{SiO}_{2}$ is extremely active to $\mathrm{HF}, \mathrm{Si}$ is immune to HF. 
In 2011, Naguib et al found that by selective etching of $\mathrm{Al}$ from $\mathrm{Ti}_{3} \mathrm{AlC}_{2}$, few nanometerthick nanocrystal can be produced. [20] $\mathrm{Ti}_{3} \mathrm{AlC}_{2}$ is a typical MAX phase with nanolaminated structure. The titanium carbide layers are interleaved with Al layers. The carbide layers are covalently bonded, which is very strong and stable. On the other hand, the $\mathrm{Al}$ layers are weakly bonded. Immersing it in $\mathrm{HF}$, the $\mathrm{Al}$ layers are quickly removed, while the $\mathrm{Ti}_{3} \mathrm{C}_{2}$ layers are preserved. A simplified reaction path is proposed as shown in the equation below. As shown in the schematic below, the $\mathrm{Al}$ layers are removed by $\mathrm{HF}$, and $\mathrm{Ti}_{3} \mathrm{C}_{2}$ layers are terminated with -OH or -F functional group. Considering the similarity with Graphene, they called it MXene.

$$
\begin{gathered}
\mathrm{Ti}_{3} \mathrm{AlC}_{2}+3 \mathrm{HF}=\mathrm{AlF}_{3}+3 / 2 \mathrm{H}_{2}+\mathrm{Ti}_{3} \mathrm{AlC}_{2} \\
\mathrm{Ti}_{3} \mathrm{C}_{2}+2 \mathrm{H}_{2} \mathrm{O}=\mathrm{H}_{2}+\mathrm{Ti}_{3} \mathrm{C}_{2}(\mathrm{OH})_{2} \\
\mathrm{Ti}_{3} \mathrm{C}_{2}+2 \mathrm{HF}=\mathrm{H}_{2}+\mathrm{Ti}_{3} \mathrm{C}_{2} \mathrm{~F}_{2}
\end{gathered}
$$

(a)

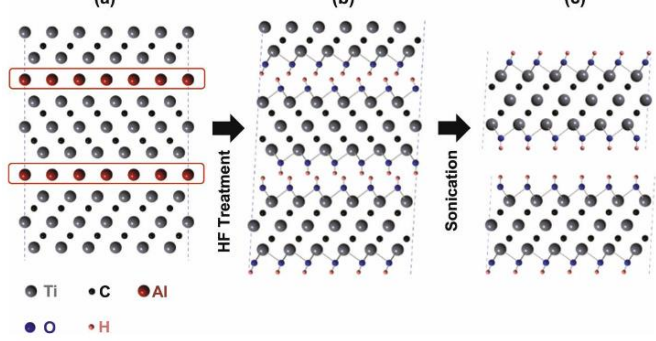

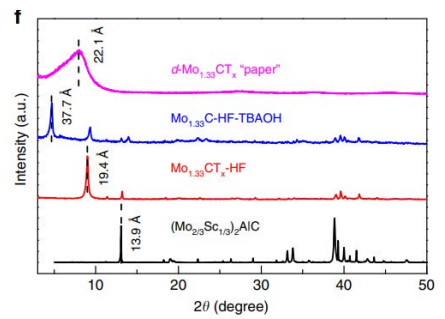

Figure 14. schematic of the etching process and corresponding features in XRD.

Following the success with $\mathrm{Ti}_{3} \mathrm{AlC}_{2}$, Naguib et al also showed that a family of twodimensional metal carbide and carbonitride can be made, including $\mathrm{Ti}_{2} \mathrm{C}, \mathrm{Ta}_{4} \mathrm{C}_{3}$, and $\mathrm{Ti}_{3} \mathrm{CN}$, etc. [21] In the coming years, several new MXenes are produced, such as $\mathrm{Mo}_{2} \mathrm{TiC}_{2} \mathrm{MXene}$ [39] and $\mathrm{Mo}_{2} \mathrm{C}$ MXene [58].

An easy way to monitor the formation of MXene is via XRD. With the removal of $\mathrm{Al}$ and replacement of surface termination, the 3D structure of MAX phase is destroyed. The peaks corresponding to MAX phase in XRD pattern would diminish. A new peak or sometimes a set of new peaks at low angle appears with the formation of MXene. For example, in Figure 14, before etching the first peak is located at $13^{\circ}$ corresponding to (002) peak with an interspacing of $13.9 \AA$. After etching, a new peak at $19.4 \AA$ appears.

\subsubsection{In situ formed HF}

As mentioned in the above section, metal carbide layers are much stronger than the Al layers, which makes the selective etching possible. However, the carbide layers are not immune to HF. 
To some extent, they also react with HF. For example, over etched sample shows pores on the 2D sheets and the layers are more fragmented comparing to sample etched in milder condition. Thus, it's beneficial to etch it in mild condition.

Ghidiu et al found that by reacting with a combination of $\mathrm{LiF}$ and $\mathrm{HCl}$, MXene can be produced with high crystalline quality [27]. They also show that the electrochemical performance is improved.

When $\mathrm{LiF}$ is dissolved in $\mathrm{HCl}$, it follows the reaction,

$$
\mathrm{LiF}+\mathrm{HCl}=\mathrm{LiCl}+\mathrm{HF}
$$

in which HF is formed in situ. As shown in REF [27], the in situ formed HF has less impact on the $\mathrm{Ti}_{3} \mathrm{C}_{2}$ carbide layers, so large and smooth $2 \mathrm{D}$ layers can be produced. On the contrary, HF produced MXene generally has higher degree of defects.

The same concept is also applied to other combination of F containing salts with strong acid, such as $\mathrm{NH}_{4} \mathrm{~F}+\mathrm{HCl}$.

Another effect of the salts/strong acid etching is the intercalation of ions between the carbide layers. In the process of $\mathrm{LiF}+\mathrm{HCl}$ etching, there's $\mathrm{Li}$ ions in the etching environment. Hydrated $\mathrm{Li}$ ions simultaneously intercalated into MXene layers. Thus, after $\mathrm{LiF}+\mathrm{HCl}$ etching, it's possible to delaminate the MXene directly without additional intercalation.

\subsubsection{Molten salt etching}

In 2016, Urbankowski et al. used molten fluoride salts to etch $\mathrm{Ti}_{4} \mathrm{AlN}_{3}$ to produce $\mathrm{Ti}_{4} \mathrm{~N}_{3}$ MXene, [59] while earlier attempts to etch it with HF failed.

In 2019, $\mathrm{Li}$ et al used molten $\mathrm{ZnCl}_{2}$ to treat MAX phases. [60] Via a two steps reaction, $\mathrm{Ti}_{3} \mathrm{AlC}_{2}$ transform to $\mathrm{Ti}_{3} \mathrm{ZnC}_{2}$, and finally to $\mathrm{Ti}_{3} \mathrm{C}_{2} \mathrm{Cl}_{2}$.

\subsection{From MXene multilayer to single sheets}

After chemical etching, MXene is in the form of multilayers, as shown in Figure 15. After the removal of $\mathrm{Al}$ from MAX phase, the surface was terminated with functional groups, including $-\mathrm{OH},-\mathrm{F}$, and $=\mathrm{O}$, etc. The two adjacent layers are weakly bonded by van der Waals force.

For actual applications, either restacked papers or mono-dispersive MXene nanosheets in solution are preferred. We use several techniques to separate them into individual MXene nanosheets. 


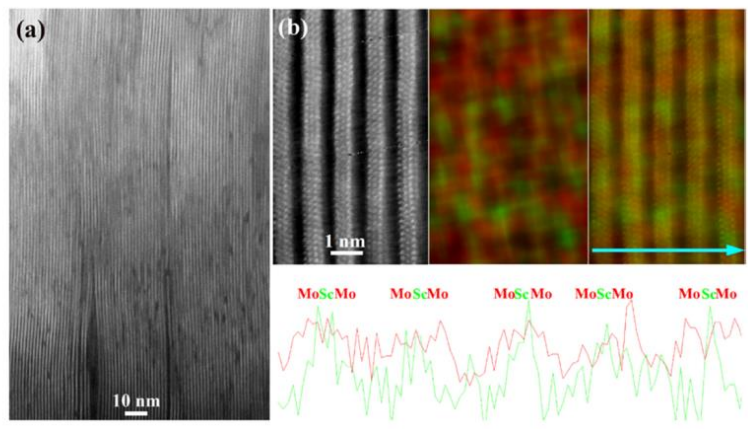

Figure 15 STEM micrograph of the cross section view of $(\mathrm{MoSc})_{3} \mathrm{C}_{2}$ MXene multilayer produced from $(\mathrm{Mo}, \mathrm{Sc})_{3} \mathrm{AlC}_{2}$.

As the layers are loosely bonded, simply sonication in water is enough. However, simply sonication can only produce limited concentration in the MXene dispersion, which is not enough for most applications.

The MXene surface are terminated with functional groups, i.e. -F, -OH, etc, resembling the functional group terminated graphene oxide. Inspired by the knowledge from Graphene study, Mashtalir et. al. tried to reduce $\mathrm{Ti}_{3} \mathrm{C}_{2}(\mathrm{OH})_{\mathrm{x}} \mathrm{O}_{\mathrm{y}} \mathrm{F}_{\mathrm{z}}$ into a hypothetical $\mathrm{Ti}_{3} \mathrm{C}_{2}$ without termination by treating with hydrazine monohydrate $\mathrm{N}_{2} \mathrm{H}_{4} \cdot \mathrm{H}_{2} \mathrm{O}$ (HM). However, instead of reducing it, hydrazine intercalates into MXene layers and expand the interlayer distance. The intercalation and increased interlayer spacing make the exfoliation much easier.

Subsequently, various intercalation agent has been found, such as isopropylamine, [61] and TBAOH [62]. TBAOH is particularly useful for various MXene. The effect of intercalation can be readily seen in XRD. For example, in Fig 14d, the interlayer distance change from $19.4 \AA$ in the as etched MXene to $37.7 \AA$ in the $\mathrm{TBA}^{+}$intercalated MXene. After intercalation with $\mathrm{TBAOH}$, most MXene can be readily delaminated, by hand shaking in water.

After delamination, usually we use centrifuge to separate the delaminated layers from those thick layers. After centrifuging, only single or few layers MXene remain in the supernatant. The supernatant is kept for further process or directly used for test.

\subsubsection{MXene electrodes}

For energy storage applications, usually we need to assemble MXene as an electrode. Typically, we filtrate delaminated MXene suspension into paper. A typical Scanning Electron Microscope image of the cross section of a filtrated MXene paper is shown in Fig.16. During the filtration process, MXene sheets stack on each other and form well aligned paper. After filtration, it can be peeled off from the filter paper as free standing paper. Then it can be cut into desired size and used as electrodes, for example, for supercapacitor.

The solution processability of MXene offers many other ways to assemble into electrodes. A uniform MXene electrodes can be deposited on glass by spin coating[63]. It can also be deposited onto conductive surface by electrochemical polymerization[30]. 


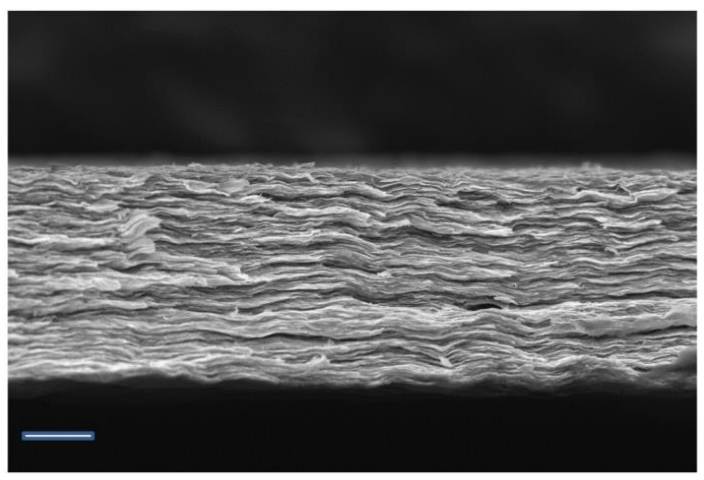

Figure 16. SEM image of a 3 micron thick $\mathrm{Mo}_{1.33} \mathrm{C}$ MXene paper produced by filtration of MXene dispersion. 


\section{Materials characterization: structure and composition}

\subsection{Crystal structure and symmetry operation}

crystal structure describes how the atoms are arranged in a material. Crystal consists of periodic array of atoms. To describe a crystal, we only need to describe the periodic unit, the unit cell. Figure 17 shows the unit cell of an $i$-MAX, $\left(\mathrm{Mo}_{2 / 3} \mathrm{~Tb}_{1 / 3}\right)_{2} \mathrm{AlC}$. It consists of $8 \mathrm{~Tb}, 16$ $\mathrm{Mo}, 12 \mathrm{Al}$, and $12 \mathrm{C}$ atoms. Each atom needs three coordinates $(\mathrm{x}, \mathrm{y}, \mathrm{z})$ to describe the position in the unit cell. We also need parameters to describe the size, i.e. lattice constant $a, b$, and $c$; and parameters to describe the shape, i.e. $\alpha, \beta$, and $\gamma$ to describe the angle between the $a, b$, and c. Thus, in total one needs $48 * 3+6=150$ parameters, which is not feasible. Instead, we use symmetry operators to relate the atoms in the unit cell. The symmetry operators in space group $\mathrm{C} 2 / \mathrm{c}$ are 1: E (identity), 2: 2-fold axis, 3: inversion center, 4: glide plane, and C-centering. Given the position of one $\mathrm{Tb}$ atoms, for example $\mathrm{Tb} 1(0.9576,0.4233,0.1134)$, the position of the remaining $7 \mathrm{~Tb}$ atoms can be generated by the eight symmetry operators, i.e. applying 2fold axis operator on $\mathrm{Tb} 1$ leads to $\mathrm{Tb} 2(0.9576,-0.4233,0.6134)$. In addition, atoms on special position have less degree of freedom. For example, $4 \mathrm{C}$ atoms on $4 d$ Wyckoff position are not allowed to move, and their positions are fixed at $\mathrm{C} 1(0.25,0.25,0.5), \mathrm{C} 2(0.25,0.75,0), \mathrm{C} 3(0.75$, $0.75,0.5)$, and $\mathrm{C} 4(0.75,0.25,0)$. After symmetry consideration, we reduce the number of free parameters to 16 for atom coordinates and 4 for lattice parameter.
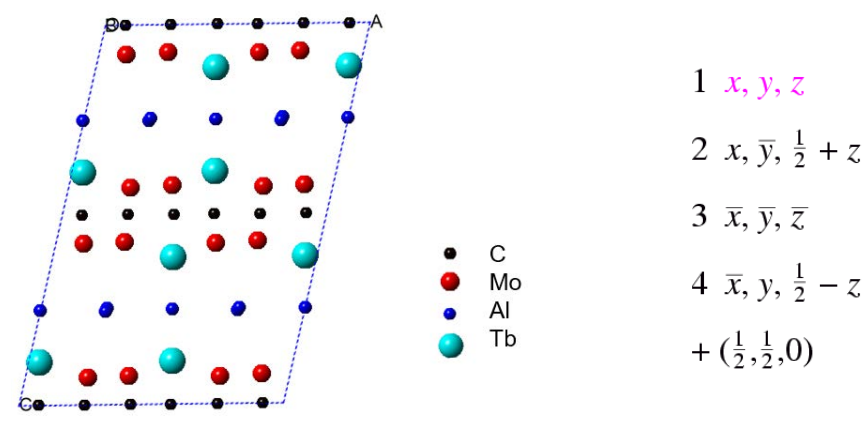

Figure 17 structure and symmetry operations of $\left(\mathrm{Mo}_{2 / 3} \mathrm{~Tb}_{1 / 3}\right) \mathrm{AlC}$.

\subsection{X-ray diffraction}

$\mathrm{X}$-ray diffraction is a very powerful technique for materials science. We routinely use Xray to do phase analysis, to study crystal structure, to evaluate the sample quality, etc. 


\subsubsection{Bragg's law}

The foundation of X-ray diffraction or any diffraction experiment is the Bragg's law. Bragg diffraction from a crystal occurs when

$$
n \lambda=2 d \sin \theta
$$

where the $\lambda$ is the wavelength, $d$ is the lattice spacing, and $\theta$ is half of the scattering angle. It's depicted in the schematic in Fig. 18. In a typical diffraction experiment, for example lab-based $\mathrm{XRD}, \lambda$ is $1.54 \AA$ from $\mathrm{Cu} \mathrm{K}_{\alpha}$, the lattice spacing can be calculated from the measured $\theta$.

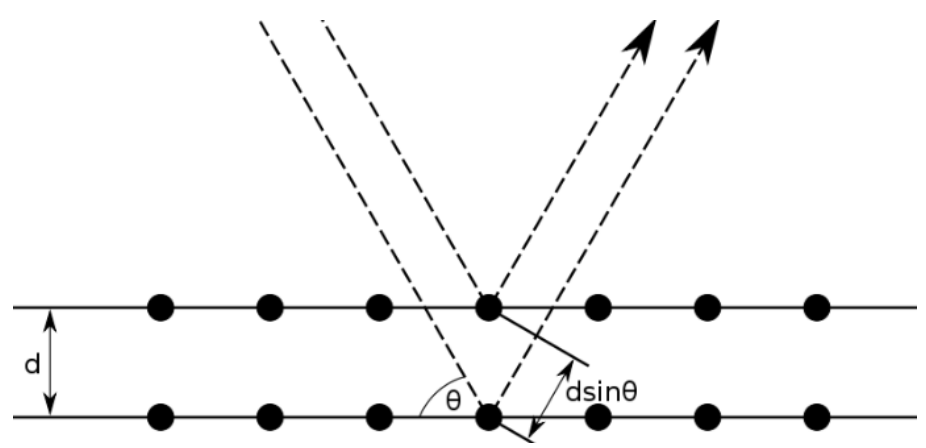

Figure 18 schematic of the Bragg diffraction.

\subsubsection{Phase analysis}

The first step is always to check if the sample you just made is what you aimed for. The simplest way is to do a 2theta-omega scan in a Bragg-Brentano geometry. By comparing the obtained pattern with the standard pattern in database, one can quickly find out what phases are in the sample. For example, in Fig. 19a several peaks can be indexed with a minor impurity phase $\mathrm{Mo}_{2} \mathrm{C}$ and the remaining peaks can be indexed with the $i$-MAX.

\subsubsection{Rietveld refinement}

We start with a model based on symmetry restriction with free parameters. Based on the model, we calculate the structural factor and compare with experimental observation. Then optimize the free parameters to obtain the minimum difference between experimentally pattern and calculated pattern, which is represented by $\chi^{2}, \chi^{2}=(\text { Exp.-Cal. })^{2}$. In the case of structural refinement of $i$-MAX, the free parameters are the 16 atom coordinates and 4 lattice parameters mentioned above.

The purposes of refinement are twofold, (1) to compare different models and (2) to obtain atom coordinates and lattice parameters. For example, Figure 19b shows the Rietveld refinement of XRD pattern of $\left(\mathrm{Mo}_{2 / 3} \mathrm{~Tb}_{1 / 3}\right)_{2} \mathrm{AlC}$. The reasonably well fitting was achieved by assuming the proposed $C 2 / c$ structure, with agreement factor $\mathrm{Rp}=9.60 \%$, $\mathrm{Rwp}=14.4 \%$. Another candidate structure with space group $\mathrm{Cmcm}$ leads to worse agreement. Then we can conclude that the proposed $C 2 / c$ structure is better than the $C m c m$ one. At the same time, lattice parameters and atom coordinates are obtained. 

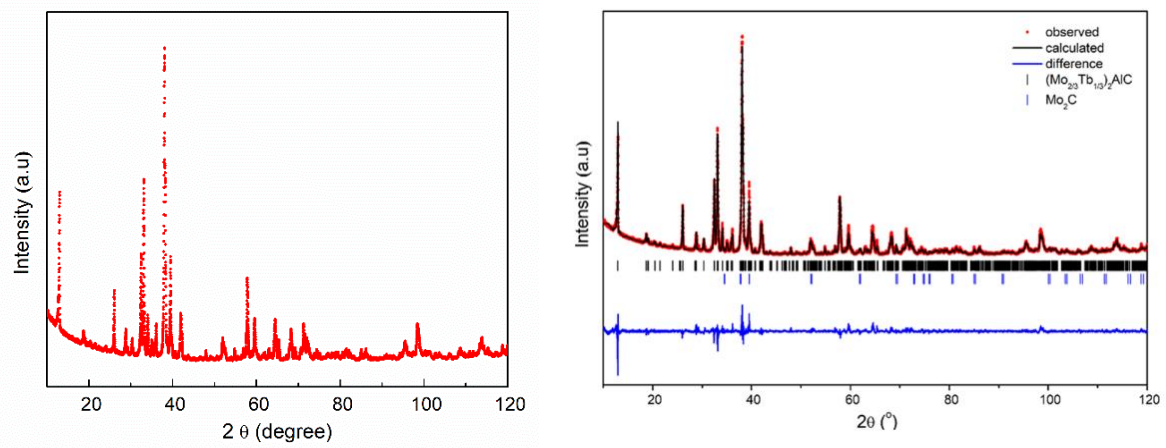

Figure 19. a. XRD pattern of $\left(\mathrm{Mo}_{2 / 3} \mathrm{~Tb}_{1 / 3}\right)_{2} \mathrm{AlC}$. b. and it's Rietveld refinement.

\subsection{Transmission electron microscopy (TEM)}

In this thesis, TEM are used to study the structure and composition of materials, by using Scanning transmission microscopy (STEM), selective area electron diffraction (SAED), and energy dispersive X-ray spectroscopy (EDX).

\subsubsection{STEM}

Figure 19 shows a simplified diagram of STEM. Electron is focused by the condenser lenses to a small spot, with spot size (electron beam size) $0.1 \sim 2 \mathrm{~nm}$. By scanning the small spot across the sample, images can be generated by collecting signal from every spot. High-angle annular dark-field imaging is usually used. At high angle, the contrast of the signal is dominated by Zcontrast, which is very easy to interpret as the intensity directly corresponds to the mass of the atoms. For example, in a STEM image of $\left(\mathrm{Mo}_{2 / 3} \mathrm{Sc}_{1 / 3}\right) \mathrm{AlC}$ as shown in Fig. 20, Mo appears to be brightest, $\mathrm{Al}$ and $\mathrm{Sc}$ is relatively weak, and $\mathrm{C}$ is too weak to be seen.

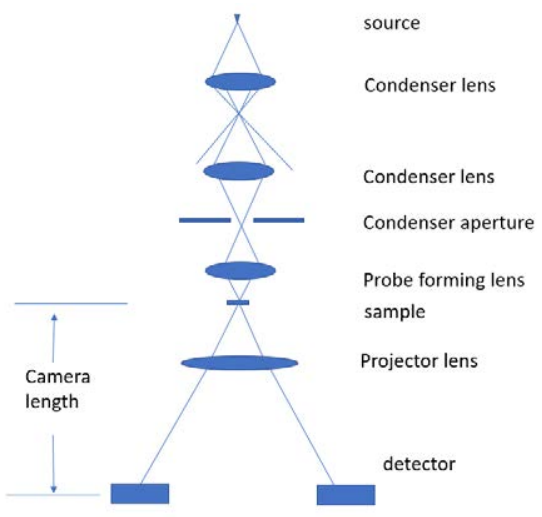

Figure 20. A simplified diagram of STEM. 


\subsubsection{Selected area electron diffraction (SAED)}

Selected area electron diffraction is very useful for identifying the crystal structure. Electron diffraction pattern is a projection of the reciprocal lattice. Figure 21 shows the STEM image and SAED pattern of $\left(\mathrm{Mo}_{2 / 3} \mathrm{Sc}_{1 / 3}\right)_{2} \mathrm{AlC}$. When the diffraction pattern is taken along zone axes, it's easy to index the diffraction spot. for example along [010] in Figure 14a, we can see that the angle between (002) and (-200) is larger than $90^{\circ}$, and (00l) and (l00) with $l=$ odd are forbidden. With this information, we can exclude a candidate structure with $\mathrm{Cmcm}$ structure.
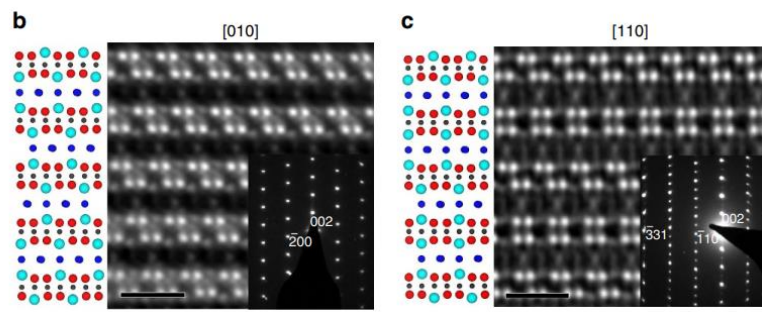

d

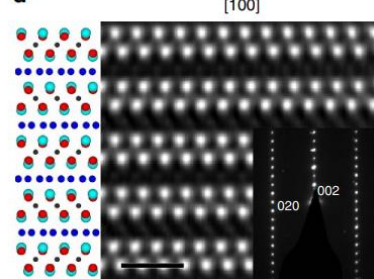

Figure 21 STEM images and SAED pattern of $\left(\mathrm{Mo}_{2 / 3} \mathrm{Sc}_{1 / 3}\right)_{2} \mathrm{AlC}$.

\subsection{Scanning electron microscopy (SEM)}

SEM are commonly used to study the morphology of the sample. Similar with TEM, SEM also uses a focused electron beam as probe. When the sample is hit by electron beam, many signals can be produced, including secondary electron, backscattered electron, and Emitted xray, etc. By collecting each signal, we could get information on the morphology and composition.
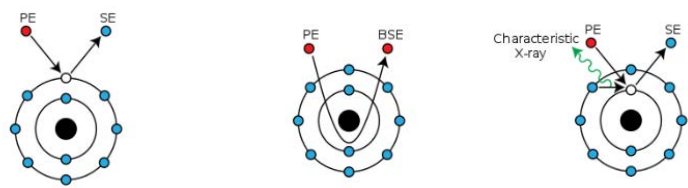

Figure 22 schematic of the formation of different signals. Figure adapted from Wikipedia.

Figure 22 shows the mechanism of the three major signals that are used in SEM analysis. Mostly we use secondary electron signal to study the morphology of MAX phase and MXene. The characteristic $\mathrm{x}$-ray emission will be discussed in the next section EDX.

\subsection{Composition analysis by EDX}

Energy dispersive X-ray spectroscopy is very useful for the quantification of the composition of materials. Figure 23 shows the interaction between incident electron and atom. A high energy incident electron beam can excite an inner shell leaving a hole in the inner shell, for example $K$ shell or $L$ shell. Then an electron in the higher energy shell will refill the hole in the inner shell and emitting X-rays with certain energy, the energy being the energy difference between two shells. Each element has a unique atomic structure, which in turn gives a unique set of peaks in the EDX spectrum. By checking the position of these peaks and 
matching with standard, we could identify the constituting elements in the sample. The intensity of the peaks corelates with the amount of each element. The intensity of the peaks can be used to quantify the ratio between each element. EDX can be performed either in SEM or TEM.

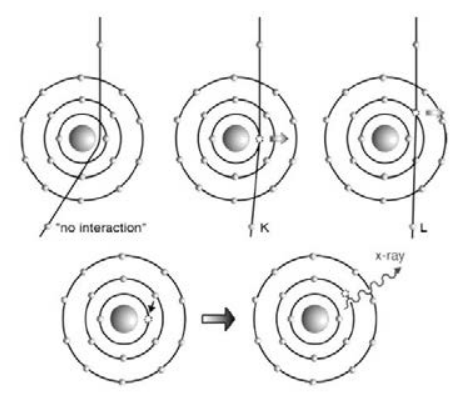

Figure 23 schematic of the EDX transition.

\subsection{Neutron diffraction for the study of crystal structure}

The same as X-ray diffraction, the diffraction condition from a crystal for neutron is given by Bragg's law. It can be used for the study of crystal structure as a complement to X-ray diffraction.

X-ray interact with the electron cloud of the atoms; the amplitude of the scattered wave called the atomic form factor increases with the atomic number. Thus, X-ray diffraction is not sensitive to light elements such as carbon, and cannot differentiate neighboring elements. Neutron on the other hand, interact with the nucleus of the atoms. It's especially sensitive to light elements like Hydrogen and carbon. For the study of MAX phase, for example we used neutron diffraction to verify the carbon position in $i$-MAX.

Similar with XRD refinement, Rietveld refinement based on neutron diffraction pattern can verify the structure and obtain parameters on the atom and lattice, as shown in Fig. 24. 


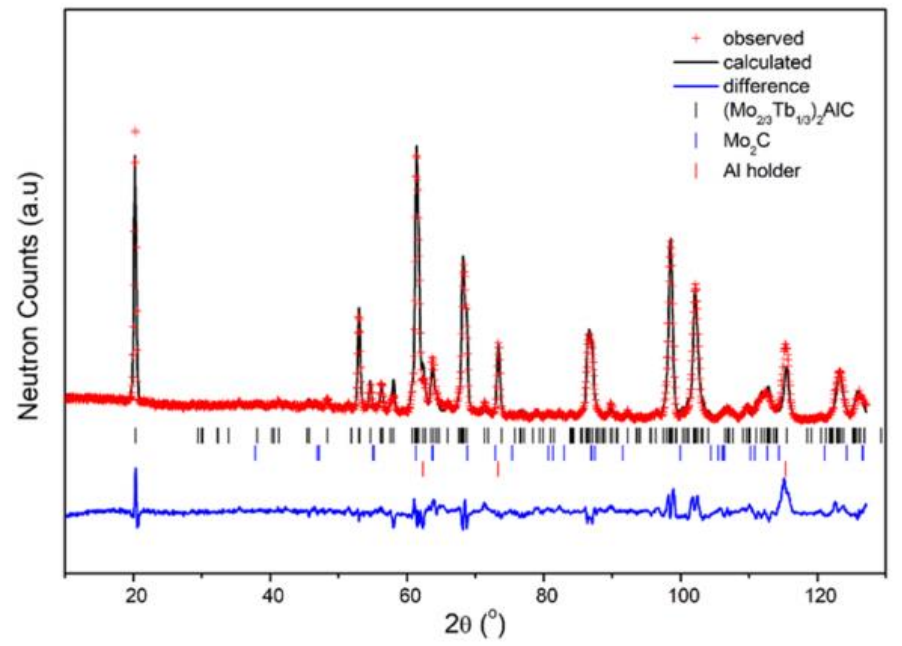

Figure 24. Rietveld refinement of neutron diffraction pattern of $\left(\mathrm{Mo}_{2 / 3} \mathrm{~Tb}_{1 / 3}\right)_{2} \mathrm{AlC}$. 


\section{Magnetic structure and magnetic MAX phases}

\subsection{Magnetic structures}

In some crystals, atoms or ions can have unpaired electrons. Through exchange interaction, these localized moments can be arranged in a certain type of long-rang order.

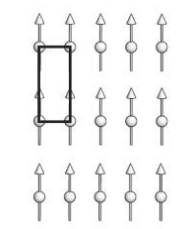

Ferromagnetic

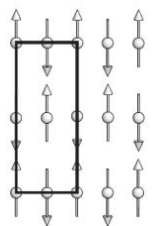

Antiferromagnetic

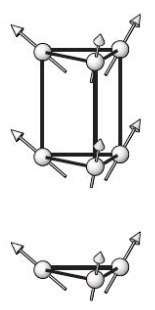

Umbrella

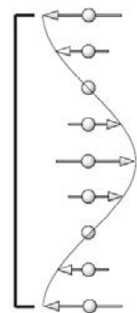

Sine structure

Figure 25. several typical type of magnetic structures.

Figure 25 shows several types of magnetic structure. The spins can be arranged in simple Ferromagnetic, antiferromagnetic structures, and more complicated structures like Umbrella structure or Sine structures, etc. Similar with crystal structure, to describe a magnetic structure, we only need to describe the structure of a unit cell. The rest atoms in a crystal can be the translation of the unit cell.

The magnetic structure does not necessarily have the size as the unit cell of crystal structure. A ferromagnetic structure has the same size as the crystal structure. The as shown Sine structure can be many times larger than the crystal structure. It's not possible to describe all the atoms in the whole magnetic unit cell. Usually we use the propagation vector formalism to describe the unit cell.

\subsection{1 propagation vector formalism}

As an example, the magnetic structure in Fig. 26. is two times larger along $c$ axis than the crystal structure. Instead of describing all atoms in the magnetic cell, we can describe the atoms in the crystal unit cell and gives the relation between two atoms at equivalent position.

$$
\mathrm{m}_{\mathrm{j}}=\Psi_{j}^{k} e^{-2 \pi i k \cdot t}
$$



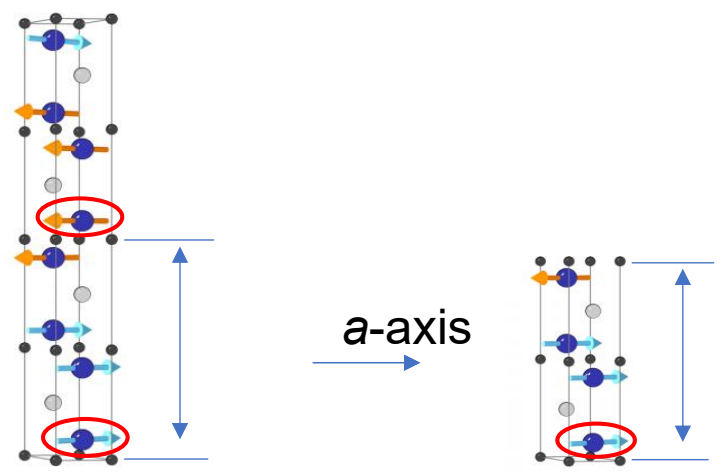

Figure 26 size of crystal structure and magnetic structure.

For example, the spin $m_{1}$ in red circle can be describe as $\Psi=(100)$. The state of $m_{1}$ can be found

$$
\mathrm{m}_{2}=\Psi_{j}^{k} e^{-2 \pi i k \cdot t}=(100) \exp \left[-2 \pi \mathrm{i}\left(\begin{array}{lll}
0 & 0 & 1 / 2
\end{array}\right) \cdot\left(\begin{array}{lll}
0 & 0 & 1
\end{array}\right)\right]=\left(\begin{array}{lll}
-1 & 0 & 0
\end{array}\right)
$$

In this way, instead of describing 8 atoms, only 4 atoms in the crystal unit cell are needed. It will be extremely important in case of large magnetic unit cell.

\subsubsection{Magnetic symmetry}

In a crystal structure, atoms are related by the symmetry operators. For example, in a unit cell of $i$-MAX structure space group 15, there are 48 atoms. It's impossible to determine the atom coordinates for each atom one by one. Instead, the position of all the eight $\mathrm{Tb}$ atoms are related by the symmetry operator listed below. We only need to determine the coordinates of $\mathrm{Tb}_{1}(\mathrm{x}, \mathrm{y}, \mathrm{z})$. Thus, we could reduce the free parameter from 24 to 3.

Similarly, the relation between spins in magnetic structures are constrained by magnetic symmetry. The magnetic symmetry consists of crystallographic symmetries and time inversion. Without symmetry consideration, magnetic structure determination can be very difficult and prone to lead to wrong solution.

As an example, let's consider a magnetic structure of a typical $i$-MAX, $\left(\mathrm{Mo}_{2 / 3} \mathrm{~Tb}_{1 / 3}\right) \mathrm{AlC}$ with $\mathrm{k}=\left(\begin{array}{lll}0 & 0 & 0\end{array}\right)$, i.e. the magnetic structure has the same size as crystal structure. In this material, only $\mathrm{Tb}$ atoms possess localized moment. In one unit cell, there are $8 \mathrm{~Tb}$ atoms.

The symmetry operators of the crystal structure

$\begin{array}{llll}\text { Tb1 } & \text { Tb2 } & \text { Tb3 } & \text { Tb4 } \\ (\mathrm{x}, \mathrm{y}, \mathrm{z}) & (-\mathrm{x}, \mathrm{y},-\mathrm{z}+1 / 2) & (-\mathrm{x},-\mathrm{y},-\mathrm{z}) & (\mathrm{x},-\mathrm{y}, \mathrm{z}+1 / 2)\end{array}$


The position of the four $\mathrm{Tb}$ atoms are given above, and the other four $\mathrm{Tb}$ atoms are given by the $\mathrm{C}$-centering.

We first identify the symmetry operators which are compatible with the magnetic translation symmetry. It's easy to find out that all four operators are compatible.

Table 1. Irreducible representations for space group $C 2 / c$ with $\mathrm{k}=\left(\begin{array}{lll}0 & 0 & 0\end{array}\right)$.

\begin{tabular}{|l|c|c|c|c|}
\hline Irreps & $\{1\}$ & $\left\{2_{y} \mid 00 \mathrm{p}\right\}$ & $\{-1\}$ & $\left\{\mathrm{m}_{\mathrm{y}} \mid 00 \mathrm{p}\right\}$ \\
\hline$\Gamma_{1}$ & 1 & 1 & 1 & 1 \\
\hline$\Gamma_{2}$ & 1 & 1 & -1 & -1 \\
\hline$\Gamma_{3}$ & 1 & -1 & 1 & -1 \\
\hline$\Gamma_{4}$ & 1 & -1 & -1 & 1 \\
\hline
\end{tabular}

To simplify it, we consider its projection along $a$ axis. There are four possible magnetic models, as shown below. $\Gamma_{3}$ corresponds to a ferromagnetic structure, and others are antiferromagnetic. The projection along $b$ and $c$ axes can be considered in similar way.

By symmetry consideration, the number of free parameters is reduced from 24 to only 3 , thus greatly reducing the difficulty in solving the structure. Then the candidate models can be compared by Rietveld refinement. The model that gives the best fit to the experimental magnetic diffraction pattern would likely correspond to the spins structure.

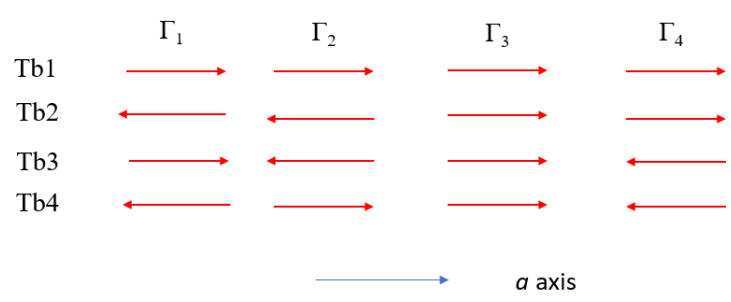

Figure 27 schematic of the four possible magnetic model.

\subsection{Magnetic MAX phases}

Magnetic MAX phase was first proposed by Luo et al theoretically [64], although the suggested $\mathrm{Fe}$-containing MAX phases, such as $\mathrm{Fe}_{2} \mathrm{AlC}$, are unlikely to be synthesized due to lack of stability.

\subsubsection{Magnetic MAX phases in thin film form}

The first experimental realization of magnetic MAX phase was done by alloying of a previously known MAX phase. In 2013, Ingason et al reported the synthesis and characterization of $\left(\mathrm{Cr}_{0.75} \mathrm{Mn}_{0.25}\right)_{2} \mathrm{GeC}[15]$. It was found to be ferromagnetic up to room temperature, with a saturated magnetic moment of $0.36 \mu_{\mathrm{B}}$ per $\mathrm{Mn}$ atom at $50 \mathrm{~K}$. 
Subsequently, more $\mathrm{Mn}$ based phases were synthesized, including $\mathrm{Mn}_{2} \mathrm{GaC}$, [16] $\left(\mathrm{Mo}_{0.5} \mathrm{Mn}_{0.5}\right)_{2} \mathrm{GaC}$, [65] and $\left(\mathrm{Cr}_{0.5} \mathrm{Mn}_{0.5}\right)_{2} \mathrm{GaC}[66]$ in thin film form. I also synthesized one of the Mn based MAX phases, $(\mathrm{VMn})_{3} \mathrm{GaC}_{2}$. The result is included as Paper 4. Notably it's the only magnetic MAX phase with a 312 stoichiometry.

Taking the prototype material $\mathrm{Mn}_{2} \mathrm{GaC}$ as an example, Ingason et al. studied the magnetic behavior of $\mathrm{Mn}_{2} \mathrm{GaC}$ by various methods. $\mathrm{Mn}_{2} \mathrm{GaC}$ shows two magnetic transitions, one at 507 $\mathrm{K}$ and another one at $220 \mathrm{~K}$ [67]. This magnetic transition is accompanied by a structural anomaly with a huge contraction of $c$-lattice parameter. [68] In addition, an additional peak appears in XRD pattern below the ordering temperature.

A more detailed study of the magnetic structure of $\mathrm{Mn}_{2} \mathrm{GaC}$ were initiated. [69] Additional Bragg peak originating from magnetic scattering was indeed observed in neutron diffraction pattern. Several candidate magnetic structures were considered by DFT calculations and a socalled $\mathrm{A}_{4}$ structure which has a period of $2 c$ was proposed. However, the suggested $\mathrm{A}_{4}$ structure was not fully compatible with the magnetic translational symmetry, a topic which is still under investigation.

\subsubsection{Magnetic MAX phases in bulk form}

It's worth mentioning that Jaouen et al. suggested evidence for magnetic ordering in $\mathrm{Cr}_{2} \mathrm{AlC}$ and $\mathrm{Cr}_{2} \mathrm{GeC}$ [70,71]. However, NMR clearly demonstrates that both materials are paramagnetic down to $4.2 \mathrm{~K}$. [72] As pointed out by Caspi et al [37], the claimed invar like behavior found for $\mathrm{Cr}_{2} \mathrm{AlC}$ is actually very common for ceramics, which is not related to magnetism.

Liu et al. reported the observation of spin-density-wave (SDW) state in $\mathrm{Cr}_{2} \mathrm{GaN}$ [73]. Based on band structure calculation, they attributed the formation of SDW to the nesting of the Fermi surfaces. They also compared the nitride with the carbide counterpart, $\mathrm{Cr}_{2} \mathrm{GaC}$. Considering the similarity in band structure between these two materials, it's interesting that the nitride is magnetic while the carbide is not. They proposed two possible reasons, deeper N-2p level and difference in elastic properties.

There have been several attempts to synthesize Mn based MAX phases in bulk form. However, only limited amount of Mn can be incorporated into the MAX phase.

The PVD thin film growth can realize metastable structures. That a material can be synthesized in thin film form does not necessarily mean that it can be made in bulk form. For example, $\mathrm{Nd}_{2} \mathrm{GeC}$ and $\mathrm{Mn}_{2} \mathrm{GaC}$ can be synthesized in thin film form by magnetron sputtering, [74] while so far they haven't been realized in bulk form. Materials in thin film has many advantages, and at the same time has some drawbacks. As for the study of magnetic properties, there are several restrictions. If it can be synthesized in bulk form, it can be characterization by various techniques.

The first successful attempts of magnetic MAX phases in bulk form were made by partially replacing $\mathrm{Cr}_{2} \mathrm{GeC}$ with $\mathrm{Mn}$, demonstrated by Liu et. al. [75] and myself and colleagues [76]. It had been shown that Mn content up to 25\% percent can be achieved in epitaxial thin film, [15] 
however, in bulk form only around $10 \%$ can be incorporated. It's shown that with Mn doping, ferromagnetism appears and the Curie temperature, $\mathrm{T}_{\mathrm{C}}$, increases linearly with $\mathrm{Mn}$ content. Even with very small amount of $\mathrm{Mn}$, ferromagnetic ordering was observed, e.g. with $2 \% \mathrm{Mn}$ $\mathrm{T}_{\mathrm{C}}$ is about $120 \mathrm{~K}$. The highest $\mathrm{T}_{\mathrm{C}}$ observed is $320 \mathrm{~K}$ in a $10 \% \mathrm{Mn}$ sample. In comparison, the $\mathrm{T}_{\mathrm{C}}$ for the thin film sample with $25 \% \mathrm{Mn}$ is about $340 \mathrm{~K}$. The appearance of ferromagnetic ordering with very small amount of $\mathrm{Mn}$ indicate that the parent compound $\mathrm{Cr}_{2} \mathrm{GeC}_{\text {locates near }}$ the quantum critical point.

Mockute et al. studied the solid solubility of $\mathrm{Mn}$ in $\mathrm{Cr}_{2} \mathrm{AlC}$ and $\mathrm{Cr}_{2} \mathrm{GaC}$. [77] It was shown that up to $6 \%$ and $30 \% \mathrm{Mn}$ can be incorporate into $\mathrm{Cr}_{2} \mathrm{AlC}$ and $\mathrm{Cr}_{2} \mathrm{GaC}$, respectively. Hamm et al. attempted to incorporate $\mathrm{Fe}$ into $\mathrm{Cr}_{2} \mathrm{AlC}$ [78]. However, evidence for the successful incorporation of Fe into MAX phase lattice is weak.

Concluding the attempts discussed above, magnetic MAX phases in bulk form is challenging to realize. Only a few MAX phases are confirmed to be magnetic as an intrinsic property.

\subsubsection{Magnetic i-MAX phases}

As discussed above, there are metal positions in $i$-MAX structure, i.e. $\mathrm{M}^{1}$ and $\mathrm{M}^{2}$ in $\left(\mathrm{M}^{1}{ }_{2 / 3} \mathrm{M}^{2}{ }_{1 / 3}\right)_{2} \mathrm{AC}$, and the ordering mechanism provides opportunity to search for magnetic MAX phases. We have been attempting to incorporate magnetic elements into both positions, $\mathrm{M}^{1}$ and $\mathrm{M}^{2}$. In paper 1 , rare earth elements were introduced to $\mathrm{M}^{2}$ site. For the first time, magnetic rare earth elements are introduced to the MAX phase family. We studied their crystal structures and found that they crystalize in three closely related $i$-MAX structures. We then studied their magnetic properties. Initially, we studied the magnetic properties of $\left(\mathrm{Mo}_{2 / 3} \mathrm{~Tb}_{1 / 3}\right)_{2} \mathrm{AlC}$ and $\left(\mathrm{Mo}_{2 / 3} \mathrm{Er}_{1 / 3}\right)_{2} \mathrm{AlC}$ in detail by magnetization and neutron diffraction, etc. These magnetic characterization techniques will be discussed in chapter 6 .
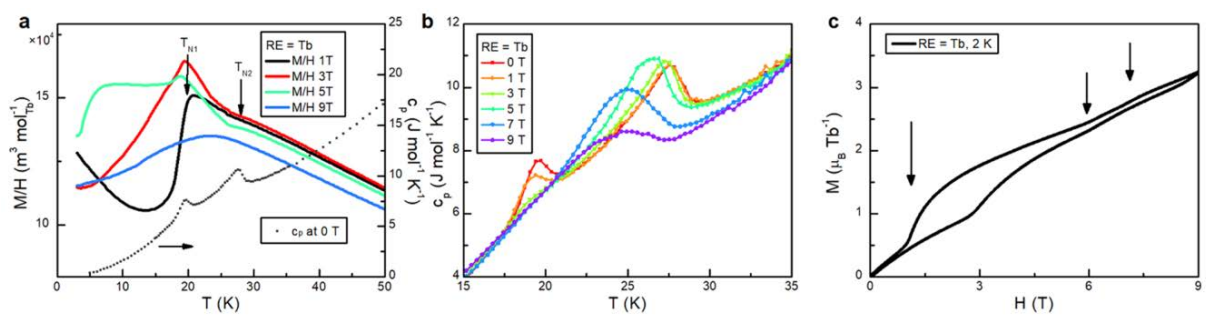

Figure 28 a. magnetization as a function of temperature, $b$.heat capacity as a function of temperature. c. Magnetization as a function of applied magnetic field.

We found that rare earth based $i$-MAX exhibit rich magnetic behaviors. For example, as can be seen in Fig. 28, (Mo2/3 $\left.\mathrm{Tb}_{1 / 3}\right)_{2} \mathrm{AlC}$ orders below $28 \mathrm{~K}$ and shows another magnetic transition at $20 \mathrm{~K}$. By neutron powder diffraction, we revealed the magnetic structure below each transition. Between $20 \mathrm{~K}$ and $28 \mathrm{~K}$, it orders with an incommensurate spin density wave structure and below $20 \mathrm{~K}$ it orders in an antiferromagnetic structure. More detail can be found in paper 1 . 
In addition, Petruhins et al. synthesized $\left(\mathrm{Mo}_{2 / 3} \mathrm{RE}_{1 / 3}\right)_{2} \mathrm{GaC}$ with $\mathrm{RE}=\mathrm{Gd}, \mathrm{Tb}, \mathrm{Dy}, \mathrm{Ho}, \mathrm{Er}$, $\mathrm{Tm}, \mathrm{Yb}$, and $\mathrm{Lu}$ [79]. Petruhins et al. synthesized $\left(\mathrm{Mn}_{2 / 3} \mathrm{Sc}_{1 / 3}\right)_{2} \mathrm{GaC}$ [80]. However, up to date the synthesis of this materials with high purity is still a challenge. Otherwise, it is very interesting to characterize the magnetic properties of this material. 


\section{Magnetic characterization}

\subsection{Magnetization}

To study a magnetic material, magnetization measurement is usually the first step. Magnetization corresponds to the density of dipole moment in a material. Different type of materials can have different response to magnetic field. By measuring the magnetization in the presence of magnetic field, it's a quick way to classify materials.

Paramagnetic materials have randomly aligned spins and can only have a weak induced magnetization in a magnetic field. Ferromagnetic materials, on the other hand, have a strong magnetization in the presence of magnetic field. Antiferromagnetic materials usually have complex response to magnetic field depending on the structure.

To study the response of a material to magnetic field, we can scan magnetization vs. applied magnetic field as shown in Fig. 29. It shows the magnetization as a function of the applied magnetic field for $\mathrm{Mo}_{4} \mathrm{Ce}_{4} \mathrm{Al}_{7} \mathrm{C}_{3}$. This material has a transition temperature at $10 \mathrm{~K}$. Above $10 \mathrm{~K}$, it's paramagnetic and below $10 \mathrm{~K}$ it's ferromagnetic. As shown in the figure, at $15 \mathrm{~K}$, in the paramagnetic state, it has a weak response to magnetic field. However, at $2 \mathrm{~K}$, it shows a strong magnetization, and displaying characteristic features of ferromagnet: remanence and coercivity. Thus, we can see that at low temperature, like at $2 \mathrm{~K}$, it's ferromagnetic and at high temperature it's paramagnetic.
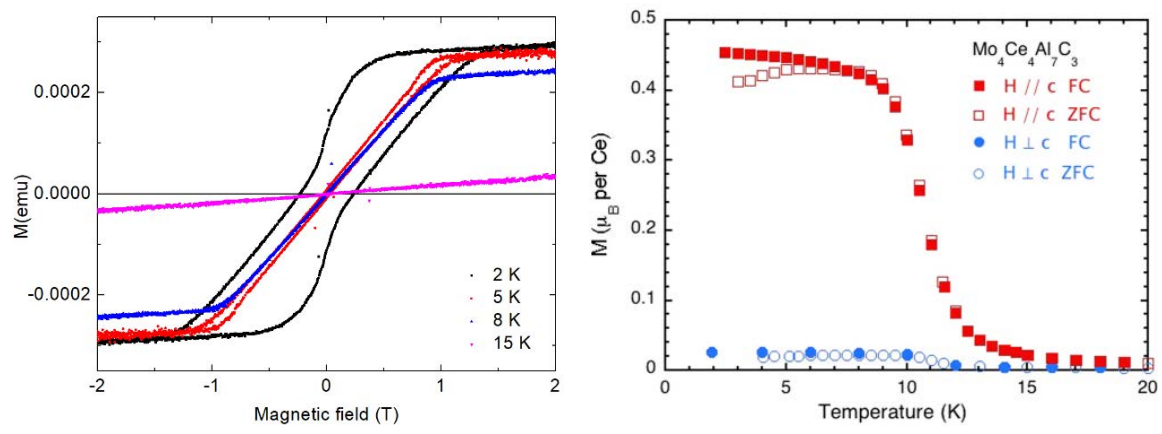

Figure 29. a. Magnetization vs. applied magnetic field for $\mathrm{Mo}_{4} \mathrm{Ce}_{4} \mathrm{Al}_{7} \mathrm{C}_{3}$. b. magnetization as a function of temperature.

We can also scan magnetization (M) as a function of temperature (T) as shown in Fig. 29b. In the $\mathrm{M}$ vs. $\mathrm{T}$ scan, the transition becomes obvious. In the figure, the transition from paramagnetic to ferromagnetic state is displayed as a sudden increase of magnetization around the transition temperature at $10.5 \mathrm{~K}$. 


\subsection{Vibrating sample magnetometer (VSM)}

Typically, we measure the magnetization by VSM. Figure 30 shows the schematic of a VSM. The sample is placed in a magnetic field and the sample is vibrating along $\mathrm{z}$ axis. The induced voltage is measured and is proportional to the magnetic moment in the sample. I mostly use a commercial equipment called PPMS (physical property measurement system). A VSM is part of the system.

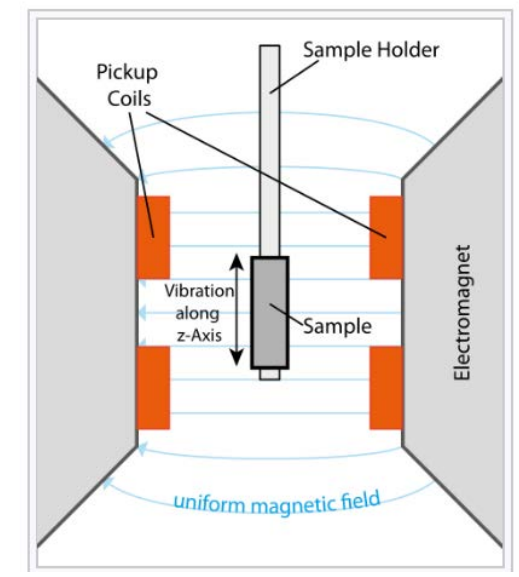

Figure 30. schematic of VSM. Figure adapted from https://en.wikipedia.org/wiki/Vibratingsample_magnetometer

\subsection{Neutron diffraction for the study of magnetism}

Neutron has a dipole magnetic moment, which can interact with magnetic field from unpaired electrons. It's possible to study magnetic structure by neutron diffraction. With neutron powder diffraction pattern, approximately,

neutron scattering $\approx$ magnetic scattering + nuclear scattering.

By measuring across the ordering temperature, we can separate the magnetic scattering from the nuclear scattering. As shown in figure 31 , at $100 \mathrm{~K}\left(\mathrm{Mo}_{2 / 3} \mathrm{~Tb}_{1 / 3}\right)_{2} \mathrm{AlC}$ is paramagnetic. The Bragg peaks are due to the crystal structure. 

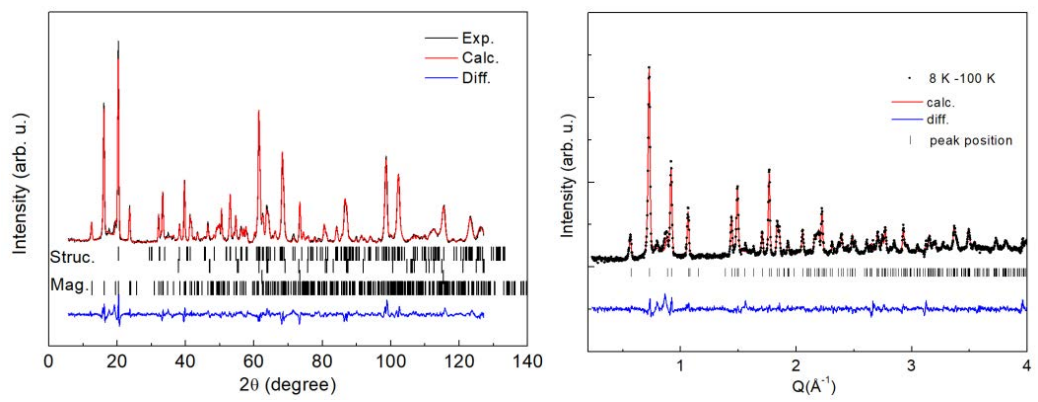

Figure 31. Rietveld refinement of neutron diffraction pattern of $\left(\mathrm{Mo}_{2 / 3} \mathrm{~Tb}_{1 / 3}\right)_{2} \mathrm{AlC}$. (a) nuclear scattering+magnetic scattering.(b) magnetic scattering only.

$\left(\mathrm{Mo}_{2 / 3} \mathrm{~Tb}_{1 / 3}\right)_{2} \mathrm{AlC}$ orders at $28 \mathrm{~K}$ and shows another transition at $20 \mathrm{~K}$. When it's cooled below the ordering temperature, the spins in $\left(\mathrm{Mo}_{2 / 3} \mathrm{~Tb}_{1 / 3}\right)_{2} \mathrm{AlC}$ orders with a periodic lattice. $\mathrm{A}$ set of new peaks appears in the diffraction pattern recorded at $8 \mathrm{~K}$, as shown in Figure 31a. It's easier to view the peaks by subtracting the nuclear scattering, magnetic scattering $\approx$ total scattering - nuclear scattering. The subtracted pattern is shown in Figure 31b. By analyzing the peak position and peak intensity in the magnetic scattering pattern, the spin structure can be obtained. 


\section{Materials characterization: electrochemical characterization}

\subsection{Cyclic voltammetry}

Mainly we use cyclic voltammetry $(\mathrm{CV})$ to characterize the electrochemical properties of MXene. Generally, the experimental setup consists of three electrodes, working electrode, reference electrode, and counter electrode. Usually the working electrode is made of the material under investigation. During an experiment, the potential between the working electrode and reference electrode ramps linearly over time and the current between working electrode and counter electrode is recorded. CV curve is then obtained by plotting current vs. applied potential. Typical CV curves can be found in Fig. 9 in previous chapter.

\subsubsection{Rate performance}

Comparing to other energy storage devices, one of the merits of supercapacitor is that it can be operated at high current density. It's important to characterize the rate performance of a supercapacitor. Fig. $9 \mathrm{~b}$ in previous chapter shows the capacitance measured at different scan rate.

\subsubsection{Cyclic stability}

Another merit of supercapacitor is the cyclic stability. As shown in Fig. 32, supercapacitor based on $\mathrm{Mo}_{1.33} \mathrm{C}$ i-MXene can operate up to 10000 charge/discharge cycles with $70 \%$ initial capacitance. In comparison, Li-ion battery typically can only operate up to several hundred cycles.

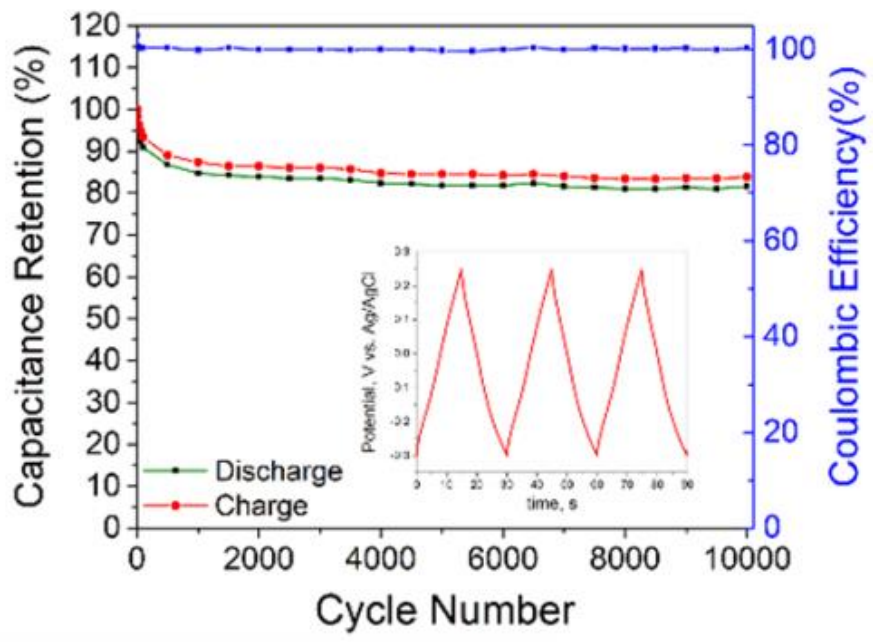

Figure 32. Cyclic stability of $\mathrm{Mo}_{1.33} \mathrm{C}$ i-MXene. 


\section{Summary of papers and my contribution to the field}

I have been working on the synthesis and characterization of nanolaminated materials and their 2D derivatives, particularly focusing on the attainable structure and magnetism. I have synthesized several nanolaminated materials, including traditional MAX phases, out-of-plane ordered MAX phases, in-plane ordered MAX phases ( $i$-MAX), and MAX phase related structures. I have been investigating these materials with various experimental techniques. In this chapter, I will summarize my published papers and my contribution to the field.

In paper 3, I reported the synthesis of $\left(\mathrm{Mo}_{2 / 3} \mathrm{Sc}_{1 / 3}\right)_{2} \mathrm{AlC}$. Before the discovery of this phase, ordering in 312 and 413 MAX phases had been reported. In 312 and 413 MAX phase structures, there are two different $\mathrm{M}$ sites. With two $\mathrm{M}$ elements preferentially occupying each site, the ordering is in the out-of-plane direction. This is opposed to $\left(\mathrm{Mo}_{2 / 3} \mathrm{Sc}_{1 / 3}\right)_{2} \mathrm{AlC}$, where Mo and $\mathrm{Sc}$ are ordered in the transition metal plane. The discovery of this material is interesting considering that the pure $\mathrm{Mo}_{2} \mathrm{AlC}$ and $\mathrm{Sc}_{2} \mathrm{AlC}$ phases are not stable. The in-plane ordering, however, can greatly reduce the formation enthalpy, and stabilize the structure. This ordering concept has been extended to the synthesis of a family of $i$-MAX phases, which is the name chosen for these types of chemically ordered materials. Most importantly, when $\left(\mathrm{Mo}_{2 / 3} \mathrm{Sc}_{1 / 3}\right)_{2} \mathrm{AlC}$ is being etched, both $\mathrm{Sc}$ and $\mathrm{Al}$ are removed. The removal of $\mathrm{Sc}$ creates vacancies in the metal carbide layers, forming an ordered vacancy MXene. The selective etching in the metal carbide layers has also been extended to other $i$-MAX phases to form a family of 2D materials. These 2D materials have been shown to be promising in several applications. I predict that the family of $i$-MAX phases and their MXenes will be greatly expanded.

In paper 1, I extended the family of $i$-MAX phases to include rare earth elements. Originally, $M$ in MAX phases were confined to early transition metal elements, and the study of magnetism in MAX phases was limited to materials based on Mn and Cr. I surveyed the rare earth elements and synthesized 11 materials, crystalizing in three different, but closely related, structures. I characterized their magnetic behavior with magnetometry, heat capacity evaluation, and neutron diffraction. Interesting magnetic characteristics were revealed, for example, $\left(\mathrm{Mo}_{2 / 3} \mathrm{~Tb}_{1 / 3}\right)_{2} \mathrm{AlC}$ showed successive magnetic transitions and displayed multiple magnetization plateaus.

In paper 2, I synthesized a nanolaminated material with structure closely related to a MAX phase, $\mathrm{Mo}_{4} \mathrm{Ce}_{4} \mathrm{Al}_{7} \mathrm{C}_{3}$. There are two $\mathrm{Ce}$ sites in the material, $\mathrm{Ce}$ in the metal carbide layer and $\mathrm{Ce}$ in the A layer. The $\mathrm{Ce}$ in the A layer is ferromagnetic ordered while the $\mathrm{Ce}$ in the metal carbide layer is nonmagnetic. In addition, the $\mathrm{Ce}$ in the carbide layer is in a mixed valence state. The mixed valence state is due to strong electron correlation. This material is a potential 
precursor for the realization of strongly correlated 2D material. Recently, Ouisse etc. demonstrated the mechanical exfoliation of this material into few layer 2D material. The next step is to characterize its physical and magnetic properties.

Paper 4 is on the synthesis and characterization of $(\mathrm{VMn})_{3} \mathrm{GaC}_{2}$. Magnetic MAX phases based on Mn was previously studied by my colleagues and other researchers. Notably, $\left(\mathrm{Cr}_{0.75} \mathrm{Mn}_{0.25}\right)_{2} \mathrm{GeC}$ shows room temperature ferromagnetic behavior and $\mathrm{Mn}_{2} \mathrm{GaC}$ shows interesting magnetic behaviors. Previous works are all based on 211 MAX phases. $(\mathrm{VMn})_{3} \mathrm{GaC}_{2}$ is the first magnetic MAX phase with the 312 structure.

In paper 5 I followed the concept of out-of-plane ordering in MAX phase proposed by others and synthesized $\mathrm{Mo}_{2} \mathrm{ScAlC}_{2}$. Previously out-of-plane ordering in $\mathrm{MAX}$ phases are reported in several materials, for example $\mathrm{Cr}_{2} \mathrm{TiAlC}_{2}$ and $\mathrm{Mo}_{2} \mathrm{TiAlC}_{2}$. I extended the family of out-ofplane ordered MAX phases. Notably, neither $\mathrm{Mo}_{3} \mathrm{AlC}_{2}$ nor $\mathrm{Sc}_{3} \mathrm{AlC}_{2}$ are stable, while $\mathrm{Mo}_{2} \mathrm{ScAlC}_{2}$ can be synthesized. It suggests that the ordering may stabilize the structure, which may be used for incorporating new elements into MAX phase family.

In paper 6, I synthesized another a nanolaminated material with structure closely related to a MAX phase. Previously, the $\mathrm{Sc}(\mathrm{RE})-\mathrm{Al}-\mathrm{C}$ system has been extensively studied. The only ternaries reported to date are $\mathrm{ScAl}_{3} \mathrm{C}_{3}$ and $\mathrm{REAl}_{3} \mathrm{C}_{3}$, where some of the $\mathrm{REAl}_{3} \mathrm{C}_{3}$ show an interesting magnetic behavior. I discovered two related novel phases in the synthesis of $\mathrm{Sc}_{2} \mathrm{Al}_{2} \mathrm{C}_{3}$ and $\mathrm{Er}_{2} \mathrm{Al}_{2} \mathrm{C}_{3}$. They may be potentially useful for producing $2 \mathrm{D}$ materials or for studying their magnetic characteristics. 


\section{References}

[1] J. Schuster, H. Nowotny, and C. Vaccaro, Journal of Solid State Chemistry 32, 213 (1980).

[2] M. W. Barsoum and T. El-Raghy, Journal of the American Ceramic Society 79, 1953 (1996).

[3] M. Sokol, V. Natu, S. Kota, and M. W. Barsoum, Trends in Chemistry (2019).

[4] A. K. Geim and K. S. Novoselov, in Nanoscience and Technology: A Collection of Reviews from Nature Journals (World Scientific, 2010), pp. 11.

[5] K. S. Novoselov, A. K. Geim, S. V. Morozov, D. Jiang, Y. Zhang, S. V. Dubonos, I. V. Grigorieva, and A. A. Firsov, science 306, 666 (2004).

[6] A. C. Neto, F. Guinea, N. M. Peres, K. S. Novoselov, and A. K. Geim, Reviews of modern physics 81, 109 (2009).

[7] S. Chen, Q. Wu, C. Mishra, J. Kang, H. Zhang, K. Cho, W. Cai, A. A. Balandin, and R. S. Ruoff, Nature materials 11, 203 (2012).

[8] C. Lee, X. Wei, J. W. Kysar, and J. Hone, science 321, 385 (2008).

[9] K. Novoselov, A. Mishchenko, A. Carvalho, and A. C. Neto, Science 353, aac9439 (2016).

[10] Y. Cao, V. Fatemi, S. Fang, K. Watanabe, T. Taniguchi, E. Kaxiras, and P. Jarillo-Herrero, Nature 556, 43 (2018).

[11] K. L. Seyler, P. Rivera, H. Yu, N. P. Wilson, E. L. Ray, D. G. Mandrus, J. Yan, W. Yao, and X. Xu, Nature 567, 66 (2019).

[12] B. Anasori, M. R. Lukatskaya, and Y. Gogotsi, Nature Reviews Materials 2, 16098 (2017).

[13] B. Huang et al., Nature 546, 270 (2017).

[14] B. Huang et al., Nature nanotechnology 13, 544 (2018).

[15] A. S. Ingason et al., Physical review letters 110, 195502 (2013).

[16] A. S. Ingason et al., Materials Research Letters 2, 89 (2014).

[17] A. S. Ingason, M. Dahlqvist, and J. Rosén, Journal of Physics: Condensed Matter 28, 433003 (2016).

[18] P. Eklund, M. Beckers, U. Jansson, H. Högberg, and L. Hultman, Thin Solid Films 518, 1851 (2010).

[19] H. Högberg, L. Hultman, J. Emmerlich, T. Joelsson, P. Eklund, J. M. Molina-Aldareguia, J.-P. Palmquist, O. Wilhelmsson, and U. Jansson, Surface and Coatings Technology 193, 6 (2005).

[20] M. Naguib, M. Kurtoglu, V. Presser, J. Lu, J. Niu, M. Heon, L. Hultman, Y. Gogotsi, and M. W. Barsoum, Advanced Materials 23, 4248 (2011).

[21] M. Naguib, O. Mashtalir, J. Carle, V. Presser, J. Lu, L. Hultman, Y. Gogotsi, and M. W. Barsoum, ACS nano 6, 1322 (2012).

[22] M. Khazaei, A. Ranjbar, M. Arai, T. Sasaki, and S. Yunoki, Journal of Materials Chemistry C 5, 2488 (2017).

[23] J.-C. Lei, X. Zhang, and Z. Zhou, Frontiers of Physics 10, 276 (2015).

[24] M. Hu, Z. Li, T. Hu, S. Zhu, C. Zhang, and X. Wang, ACS nano 10, 11344 (2016).

[25] M. R. Lukatskaya et al., Science 341, 1502 (2013).

[26] Q. Tao et al., Nature communications 8, 14949 (2017).

[27] M. Ghidiu, M. R. Lukatskaya, M.-Q. Zhao, Y. Gogotsi, and M. W. Barsoum, Nature 516, 78 (2014).

[28] X. Wang, S. Kajiyama, H. Iinuma, E. Hosono, S. Oro, I. Moriguchi, M. Okubo, and A. Yamada, Nature communications 6, 6544 (2015).

[29] M. R. Lukatskaya et al., Nature Energy 2, 17105 (2017).

[30] L. Qin, Q. Tao, X. Liu, M. Fahlman, J. Halim, P. O. Persson, J. Rosen, and F. Zhang, Nano Energy 60, 734 (2019).

[31] Z. W. Seh, K. D. Fredrickson, B. Anasori, J. Kibsgaard, A. L. Strickler, M. R. Lukatskaya, Y. Gogotsi, T. F. Jaramillo, and A. Vojvodic, ACS Energy Letters 1, 589 (2016).

[32] R. Meshkian et al., Advanced Materials 30, 1706409 (2018).

[33] G. Gao, A. P. O’Mullane, and A. Du, ACS Catalysis 7, 494 (2016). 
[34] Y. Luo, G.-F. Chen, L. Ding, X. Chen, L.-X. Ding, and H. Wang, Joule 3, 279 (2019).

[35] Z. Liu et al., Acta Materialia 73, 186 (2014).

[36] B. Anasori, J. Halim, J. Lu, C. A. Voigt, L. Hultman, and M. W. Barsoum, Scripta Materialia 101, 5 (2015).

[37] E. a. N. Caspi, P. Chartier, F. Porcher, F. Damay, and T. Cabioc'h, Materials Research Letters 3, 100 (2015).

[38] M. Dahlqvist and J. Rosen, Nanoscale 12, 785 (2020).

[39] B. Anasori, Y. Xie, M. Beidaghi, J. Lu, B. C. Hosler, L. Hultman, P. R. Kent, Y. Gogotsi, and M. W. Barsoum, ACS nano 9, 9507 (2015).

[40] M. Dahlqvist, J. Lu, R. Meshkian, Q. Tao, L. Hultman, and J. Rosen, Science advances 3, e1700642 (2017).

[41] J. Lu, A. Thore, R. Meshkian, Q. Tao, L. Hultman, and J. Rosén, Crystal Growth \& Design 17, 5704 (2017).

[42] Q. Tao et al., Chemistry of Materials 31, 2476 (2019).

[43] M. Dahlqvist, A. Petruhins, J. Lu, L. Hultman, and J. Rosen, ACS nano 12, 7761 (2018).

[44] H. Lind, J. Halim, S. Simak, and J. Rosén, Physical Review Materials 1, 044002 (2017).

[45] R. Meshkian, Q. Tao, M. Dahlqvist, J. Lu, L. Hultman, and J. Rosen, Acta Mater. 125, 476 (2017).

[46] L. Qin, Q. Tao, A. El Ghazaly, J. Fernandez-Rodriguez, P. O. Persson, J. Rosen, and F. Zhang, Advanced Functional Materials 28, 1703808 (2018).

[47] J. Wang, J. Polleux, J. Lim, and B. Dunn, The Journal of Physical Chemistry C 111, 14925 (2007).

[48] M. R. Lukatskaya, S. M. Bak, X. Yu, X. Q. Yang, M. W. Barsoum, and Y. Gogotsi, Advanced Energy Materials 5 (2015).

[49] P. Srimuk, J. Halim, J. Lee, Q. Tao, J. Rosen, and V. Presser, ACS Sustainable Chemistry \& Engineering 6, 3739 (2018).

[50] N. Kim, B. H. Lee, D. Choi, G. Kim, H. Kim, J.-R. Kim, J. Lee, Y. H. Kahng, and K. Lee, Physical review letters 109, 106405 (2012).

[51] T. M. Gesing and W. Jeitschko, Journal of solid state chemistry 140, 396 (1998).

[52] L. He, Y. Zhou, Y. Bao, Z. Lin, and J. Wang, Journal of the American Ceramic Society 90 , 1164 (2007).

[53] J. Zhou, X. Zha, F. Y. Chen, Q. Ye, P. Eklund, S. Du, and Q. Huang, Angewandte Chemie International Edition 55, 5008 (2016).

[54] J. Zhou et al., ACS nano 11, 3841 (2017).

[55] A. Gkountaras, Y. Kim, J. Coraux, V. Bouchiat, S. Lisi, M. W. Barsoum, and T. Ouisse, Small, 1905784 (2019).

[56] S. Swann, Physics in technology 19, 67 (1988).

[57] T. Ouisse, E. Sarigiannidou, O. Chaix-Pluchery, H. Roussel, B. Doisneau, and D. Chaussende, Journal of Crystal Growth 384, 88 (2013).

[58] R. Meshkian, L.-Å. Näslund, J. Halim, J. Lu, M. W. Barsoum, and J. Rosen, Scripta Materialia 108, 147 (2015).

[59] P. Urbankowski et al., Nanoscale 8, 11385 (2016).

[60] M. Li et al., Journal of the American Chemical Society 141, 4730 (2019).

[61] O. Mashtalir, M. R. Lukatskaya, M. Q. Zhao, M. W. Barsoum, and Y. Gogotsi, Advanced Materials 27, 3501 (2015).

[62] M. Naguib, R. R. Unocic, B. L. Armstrong, and J. Nanda, Dalton transactions 44, 9353 (2015).

[63] Y. Liu et al., ACS Applied Electronic Materials (2019).

[64] W. Luo and R. Ahuja, Journal of Physics: Condensed Matter 20, 064217 (2008).

[65] R. Meshkian, A. S. Ingason, U. Arnalds, F. Magnus, J. Lu, and J. Rosén, APL Materials 3, $076102(2015)$.

[66] A. Petruhins, A. S. Ingason, J. Lu, F. Magnus, S. Olafsson, and J. Rosen, Journal of Materials Science 50, 4495 (2015).

[67] I. P. Novoselova et al., Scientific reports 8, 2637 (2018).

[68] M. Dahlqvist et al., Physical Review B 93, 014410 (2016). 
[69] A. S. Ingason, G. K. Pálsson, M. Dahlqvist, and J. Rosén, Physical Review B 94, 024416 (2016). [70] M. Jaouen, P. Chartier, T. Cabioc'h, V. Mauchamp, G. André, and M. Viret, Journal of the American Ceramic Society 96, 3872 (2013).

[71] M. Jaouen, M. Bugnet, N. Jaouen, P. Ohresser, V. Mauchamp, T. Cabioc'h, and A. Rogalev, Journal of Physics: Condensed Matter 26, 176002 (2014).

[72] Z. Liu, K. Takao, T. Waki, Y. Tabata, and H. Nakamura, in Journal of Physics: Conference Series (IOP Publishing, 2017), p. 012016.

[73] Z. Liu, T. Waki, Y. Tabata, K. Yuge, H. Nakamura, and I. Watanabe, Physical Review B 88, 134401 (2013).

[74] P. Eklund, M. Dahlqvist, O. Tengstrand, L. Hultman, J. Lu, N. Nedfors, U. Jansson, and J. Rosén, Physical review letters 109, 035502 (2012).

[75] Z. Liu, T. Waki, Y. Tabata, and H. Nakamura, Physical Review B 89, 054435 (2014).

[76] Q. Tao et al., Materials Research Letters 2, 192 (2014).

[77] A. Mockuté, J. Lu, E. Moon, M. Yan, B. Anasori, S. May, M. Barsoum, and J. Rosén, Materials Research Letters 3, 16 (2015).

[78] C. M. Hamm, J. D. Bocarsly, G. Seward, U. I. Kramm, and C. S. Birkel, Journal of Materials Chemistry C 5, 5700 (2017).

[79] A. Petruhins, J. Lu, L. Hultman, and J. Rosen, Materials Research Letters 7, 446 (2019).

[80] A. Petruhins, Synthesis and characterization of magnetic nanolaminated carbides (Linköping University Electronic Press, 2018), Vol. 1918. 


\section{Papers}

The papers associated with this thesis have been removed for copyright reasons. For more details about these see:

http://urn.kb.se/resolve?urn=urn:nbn:se:liu:diva-163847 


\section{FACULTY OF SCIENCE AND ENGINEERING}

Linköping Studies in Science and Technology, Dissertation No. 2058, 2020

Department of physics, chemistry, and biology

Linköping University

SE-581 83 Linköping, Sweden

www.liu.se 